\title{
Multi-omics analysis provides insights into lignocellulosic biomass degradation by Laetiporus sulphureus ATCC 52600
}

Fernanda Lopes de Figueiredo ${ }^{1 \dagger}{ }^{\dagger}$, Ana Carolina Piva de Oliveira ${ }^{1,2 \dagger}$, Cesar Rafael Fanchini Terrasan ${ }^{1}$, Thiago Augusto Gonçalves ${ }^{1,8}$, Jaqueline Aline Gerhardt ${ }^{1}$, Geizecler Tomazetto ${ }^{3}$, Gabriela Felix Persinoti², Marcelo Ventura Rubio ${ }^{1}$, Jennifer Andrea Tamayo Peña ${ }^{5}$, Michelle Fernandes Araújo ${ }^{5}$, Maria Augusta de Carvalho Silvello ${ }^{6}$, Telma Teixeira Franco ${ }^{4}$, Sarita Cândida Rabelo ${ }^{7}$, Rosana Goldbeck 6 , Fabio Marcio Squina ${ }^{8^{*}}$ and André Damasio ${ }^{1,9^{*}}$ (1)

\begin{abstract}
Background: Wood-decay basidiomycetes are effective for the degradation of highly lignified and recalcitrant plant substrates. The degradation of lignocellulosic materials by brown-rot strains is carried out by carbohydrate-active enzymes and non-enzymatic Fenton mechanism. Differences in the lignocellulose catabolism among closely related brown rots are not completely understood. Here, a multi-omics approach provided a global understanding of the strategies employed by L. sulphureus ATCC 52600 for lignocellulose degradation.

Results: The genome of Laetiporus sulphureus ATCC 52600 was sequenced and phylogenomic analysis supported monophyletic clades for the Order Polyporales and classification of this species within the family Laetiporaceae. Additionally, the plasticity of its metabolism was revealed in growth analysis on mono- and disaccharides, and polysaccharides such as cellulose, hemicelluloses, and polygalacturonic acid. The response of this fungus to the presence of lignocellulosic substrates was analyzed by transcriptomics and proteomics and evidenced the occurrence of an integrated oxidative-hydrolytic metabolism. The transcriptomic profile in response to a short cultivation period on sugarcane bagasse revealed 125 upregulated transcripts, which included CAZymes (redox enzymes and hemicellulases) as well as non-CAZy redox enzymes and genes related to the synthesis of low-molecular-weight compounds. The exoproteome produced in response to extended cultivation time on Avicel, and steam-exploded sugarcane bagasse, sugarcane straw, and Eucalyptus revealed 112 proteins. Contrasting with the mainly oxidative profile observed in the transcriptome, the secretomes showed a diverse hydrolytic repertoire including constitutive cellulases and hemicellulases, in addition to 19 upregulated CAZymes. The secretome induced for 7 days on sugarcane bagasse, representative of the late response, was applied in the saccharification of hydrothermally pretreated grass (sugarcane straw) and softwood (pine) by supplementing a commercial cocktail.
\end{abstract}

\footnotetext{
*Correspondence: fabio.squina@gmail.com; adamasio@unicamp.br

${ }^{\dagger}$ Fernanda Lopes de Figueiredo and Ana Carolina Piva de Oliveira share first authorship

${ }^{1}$ Department of Biochemistry and Tissue Biology, Institute of Biology, University of Campinas (UNICAMP), Campinas, SP, Brazil

${ }^{8}$ Department of Technological and Environmental Processes, University of Sorocaba (UNISO), Sorocaba, SP, Brazil

Full list of author information is available at the end of the article
}

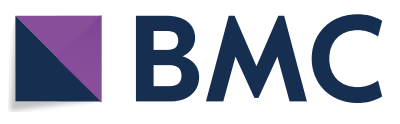

(c) The Author(s) 2021. This article is licensed under a Creative Commons Attribution 4.0 International License, which permits use, sharing, adaptation, distribution and reproduction in any medium or format, as long as you give appropriate credit to the original author(s) and the source, provide a link to the Creative Commons licence, and indicate if changes were made. The images or other third party material in this article are included in the article's Creative Commons licence, unless indicated otherwise in a credit line to the material. If material is not included in the article's Creative Commons licence and your intended use is not permitted by statutory regulation or exceeds the permitted use, you will need to obtain permission directly from the copyright holder. To view a copy of this licence, visit http://creativeco mmons.org/licenses/by/4.0/. The Creative Commons Public Domain Dedication waiver (http://creativecommons.org/publicdomain/ zero/1.0/) applies to the data made available in this article, unless otherwise stated in a credit line to the data. 
Conclusion: This study shows the singularity of L. sulphureus ATCC 52600 compared to other Polyporales brown rots, regarding the presence of cellobiohydrolase and peroxidase class II. The multi-omics analysis reinforces the oxidativehydrolytic metabolism involved in lignocellulose deconstruction, providing insights into the overall mechanisms as well as specific proteins of each step.

Keywords: Basidiomycetes, Brown-rot, Genome, Transcriptome, Proteome, CAZymes, Fenton reaction, Sugarcane by-products

\section{Background}

Wood-decay basidiomycetes are essential for the carbon cycle because of their highly specialized biomass degradation. Their metabolic systems include carbohydrateactive enzymes (CAZymes), but also non-CAZymes and other associated non-enzymatic compounds. This ability allows them to be potentially used for the production of value-added biocompounds derived from lignocellulosic biomass [1-3].

Traditionally, wood-decay basidiomycetes have been classified as brown-rot or white-rot based on the capacity to degrade plant cell wall components. Accordingly, brown rots degrade cellulose and hemicellulose while only modifying lignin. These two decay modes have been distinguished based on the reduction or absence of some enzymes, such as ligninolytic peroxidases (PODs) class II (manganese-, lignin- and versatile-peroxidases), as well as enzymes involved in cellulose degradation such as cellobiohydrolase $(\mathrm{CBH})$, lytic polysaccharide monooxygenase (LPMO) and cellobiose dehydrogenase $(\mathrm{CDH})$ [3, 4]. To compensate for the paucity of cellulolytic enzymes, some brown rots employ mechanisms for endoglucanase overproduction [5]. The lignocellulose degradation performed by brown-rot fungi involves chemical, biological and spatial relationships between fungal hyphae and the plant cell wall to perform a two-step mechanism: earlier lignocellulose oxidative (LOX) degradation mediated by Fenton reaction $\left(\mathrm{H}_{2} \mathrm{O}_{2}+\mathrm{Fe}^{2+} \rightarrow \mathrm{Fe}^{3+}+\mathrm{OH} \cdot\right)$ followed by a late hydrolytic mechanism. Key requirements for Fenton systems include mechanisms for extracellular peroxide production and iron reduction, involving extracellular fungal enzymes and metabolites, to generate reactive oxygen species (ROS) [6-9].

Most brown-rot agaricomycetes belong to the order Polyporales Gäum. Within this order, most brown-rot species belong to the "Antrodia clade", which includes the families Dacryobolaceae Jülich, Fomitopsidaceae Jülich, Laetiporaceae Jülich, and Sparassidaceae Herter, as well as a few unsolved groups [10]. L. sulphureus is considered a cosmopolitan species causing brown cubical heart rot in many deciduous and coniferous trees $[11,12]$. It is known to produce metabolites with antioxidant and antimicrobial properties $[13,14]$ and natural dyes $[15,16]$ in addition to the potential for bioremediation of treated wood [17] and decolorization of textile effluents [11]. During wood decay, L. sulphureus causes higher polysaccharide weight loss than lignin loss [18]. This fungus has superior potential to produce cellulolytic and hemicellulolytic enzymes in comparison to other representative brown rots [19] and the enzymatic repertoire secreted in the presence of carboxymethyl-cellulose (CMC) was analyzed by mass spectrometry [20]. However, the potential for lignocellulose degradation has not been explored at multi-omics level.

Omics approaches allow a deep understanding of the biology of an organism, including its behavior during growth on complex plant biomass [21]. In this work, genome sequencing followed by transcriptomic and proteomic analysis provided a global understanding of the strategies employed by L. sulphureus ATCC 52600 in the degradation of lignocellulosic by-products derived from sugarcane and Eucalyptus. In addition, a commercial enzymatic cocktail supplemented with the L. sulphureus secretome was evaluated for saccharification of hydrothermally pretreated grass (sugarcane straw) and softwood (pine).

\section{Results \\ Sequencing, annotation, and phylogenetic analysis of $L$. sulphureus ATCC 52600}

The L. sulphureus ATCC 52600 genome sequence was assembled by a combination of paired-end $(45,000,408$ sequences) and mate-pair libraries $(13,294,823$ and $13,280,039$ sequences), corresponding to $43.4 \mathrm{Mb}$ (Table 1).

Genomic features were similar to $L$. sulphureus var. sulphureus v1.0 [22]. Comparative analysis showed the strains sharing 8419 clusters of orthologous genes, with 7724 single-copy genes, which accounted for $60 \%$ and $56 \%$ of all coding sequences for the strains ATCC 52600 and var. sulphureus v1.0, respectively. The phylogenomic analysis considering whole-genome information strongly supported monophyletic clades for all families within the order Polyporales (Fig. 1). The strain ATCC 52600 clustered with $L$. sulphureus var. sulphureus v1.0 and Wolfporia cocos in the family Laetiporaceae, which, in turn, appears as a sister clade of Fibroporiaceae (Fibroporia 
Table 1 Statistical information on the genome assembly of $L$. sulphureus ATCC 52600

\begin{tabular}{ll}
\hline L. sulphureus ATCC 52600 & \\
\hline Estimated coverage & $125 x$ \\
\# contigs (>=5000 pb) & 428 \\
\# contigs (>=10,000 pb) & 375 \\
\# contigs (>=25,000 pb) & 275 \\
\# contigs (>=50,000 pb) & 213 \\
\# scaffolds & 785 \\
Total length (pb) & $43,372,605$ \\
Largest contig (pb) & $1,372,164$ \\
GC (\%) & 51.22 \\
N50 & 211,056 \\
N75 & 102,005 \\
L50 & 53 \\
L75 & 1129 \\
Number of predicted genes & 12,802 \\
\hline
\end{tabular}

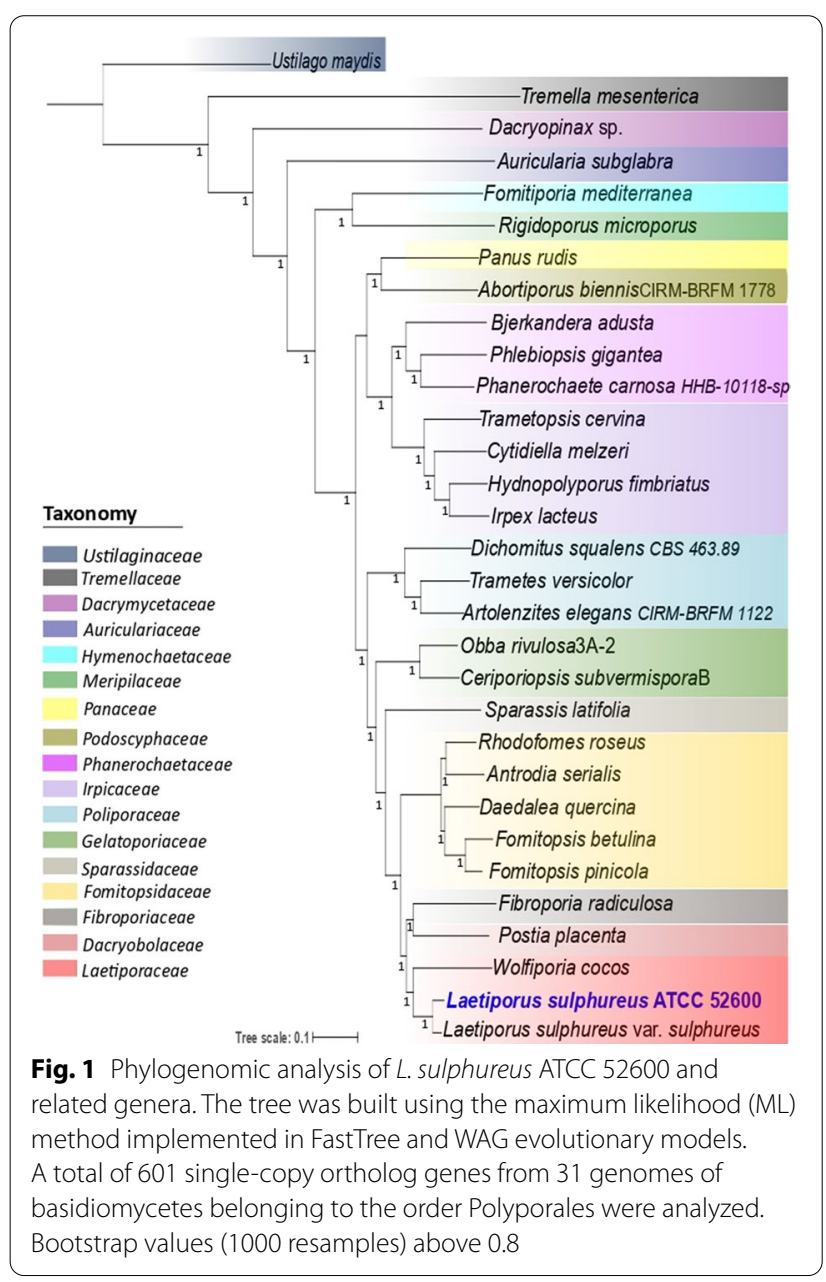

radiculosa) and closely related to Dacryobolaceae (Postia placenta).

\section{L. sulphureus ATCC 52600 genome: non-enzymatic mechanism for biomass deconstruction and non-canonical brown-rot CAZymes}

The CAZymes content was constituted of 271 modules, including 133 glycoside hydrolases (GH), 51 auxiliary activities (AA), 67 glycosyltransferases (GT), 13 carbohydrate esterases (CE), and 4 polysaccharide lyases (PL). Regarding carbohydrate-binding modules, CBM20 was found associated with GHs, in addition to the nonappended CBM13 and CBM21 (Additional file 1: Figure S1A). GHs comprised $49 \%$ of CAZymes, and the most abundant families were GH16 (19 members) and GH5 (16 members) (Additional file 1: Figure S1A). GHs repertoire for cellulose degradation also included endoglucanases (GH5), $\beta$-glucosidases (GH1, GH3), and one predicted cellobiohydrolase (GH7). A wide range of GHs associated with hemicellulose degradation such as xylan (GH10, GH43, GH115), glucans (GH16, GH55), and mannans (GH53) was identified, in addition to enzymes active on starch (GH13, GH15), pectin (GH28), chitin (GH18), and trehalose (GH37) (Fig. 2 and Additional file 2: Table S1).

The analysis showed 19\% of the predicted CAZymes assigned to AAs (Additional file 1: Figure S1A). Among them, a large number of AA3 (28 members) are grouped into the subfamilies AA3_2 (25 aryl/glucose oxidases) and AA3_3 (3 alcohol oxidases). Also, 6 members of AA1 were identified and categorized into the subfamilies AA1_1 (3 laccases), AA1_2 (1 ferroxidase), and AA1_3 (2 laccase-like multicopper oxidases). Three AA5_1 glyoxal oxidases and one AA6 benzoquinone reductase were also identified. Moreover, two genes coding for AA2 PODs were predicted, as well as AA members acting on cellulose/hemicellulose, including seven AA7 glucooligosaccharide oxidases, two AA9 lytic polysaccharide monooxygenases (LPMO), and two AA14 LPMOs (Fig. 2 and Additional file 2: Table S1).

The most prevalent CE family was CE16 (6 acetyl esterases), in addition to CE4 (2 chitin deacetylase and 1 acetyl xylan esterase), CE1 (1 acetyl xylan esterase and 1 carboxylesterase), CE8 (1 pectin methylesterase), and CE9 (N-acetylglucosamine deacetylase). Three PL14 and one PL35 were also identified. The most abundant GT family was GT2 encompassing 15 members, followed by GT8 (5 members), GT4 (4 members), and GT15, GT20, GT21, GT39, and GT69 (3 members each) (Fig. 2, Additional file 1: Figure S1A and Additional file 2: Table S1). Additionally, a wide diversity of genes involved in Fenton reaction and oxidative mechanisms was identified in the $L$. sulphureus ATCC 52600 genome, including alcohol dehydrogenases, aldo-keto reductases, catalases, ferroxidase, 

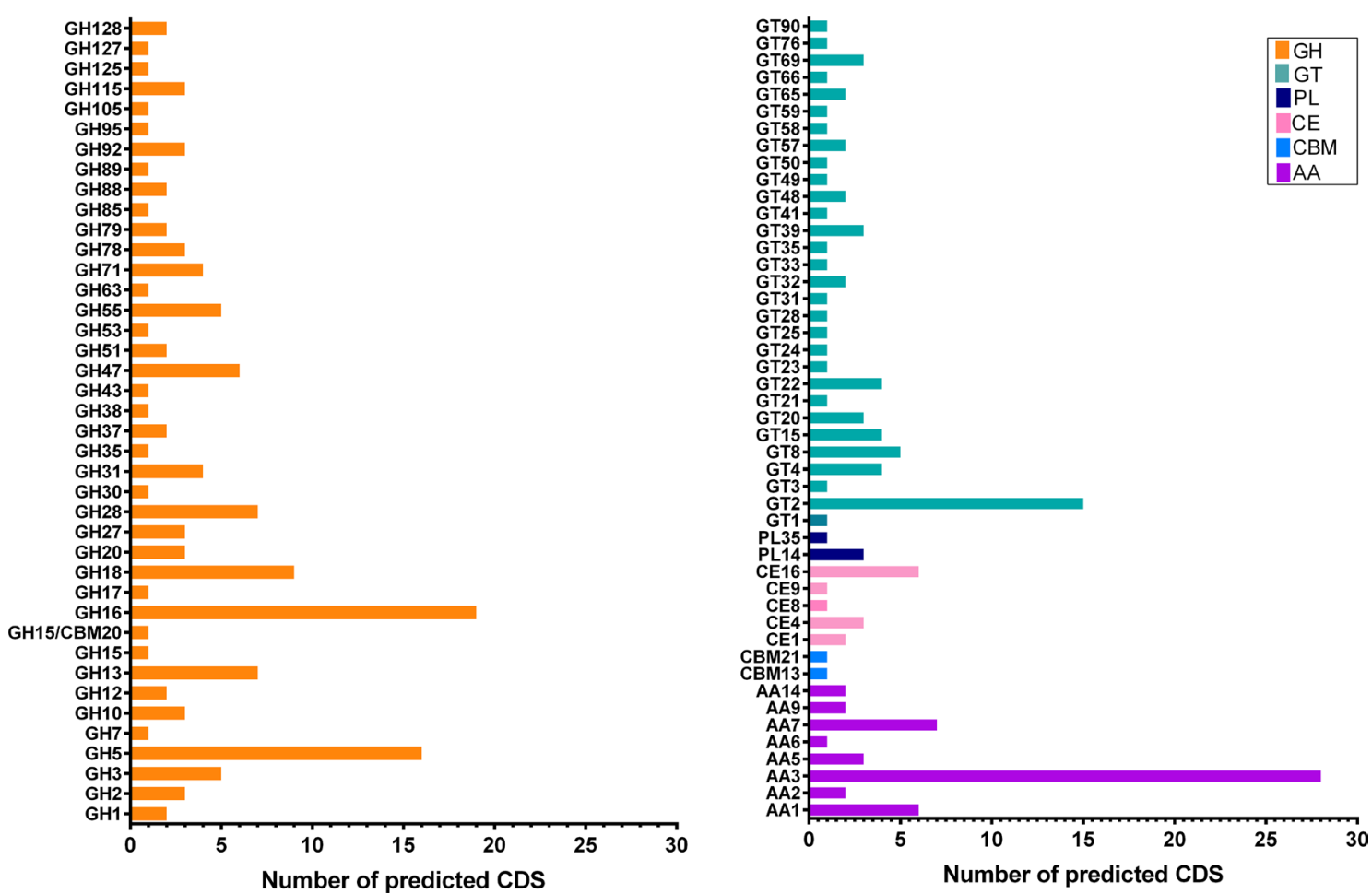

Fig. 2 L. sulphureus ATCC 52600 CAZyme-coding genes. Genome profile representing the number of predicted genes encoding CAZymes. CAZy classes: GH: glycoside hydrolases, CBM: carbohydrate-binding module, CE: carbohydrate esterase, PL: polysaccharide lyase and AA: auxiliary activities

cytochrome P450, peroxidases not assigned to CAZy domains, oxidoreductases, oxalate decarboxylase, and hydroquinone dehalogenases, the last two involved in the production of low-molecular-weight compounds (LMW) (Additional file 1: Figure S1A and Additional file 2: Table S1).

\section{L. sulphureus ATCC 52600 displays a broad-range carbohydrate metabolism and slow glucose consumption} The presence of transporters for different carbohydrates such as glucose, mannose, and trehalose in the genome motivated further analysis of the $L$. sulphureus ATCC 52600 primary metabolism (Additional file 2: Table S1). The strain was able to grow on mono-, di- and polysaccharides (Additional file 1: Figure S2A), and faster colony growth was verified on pectin, followed by galacturonic acid, xylan, arabinose, and galactomannan (Additional file 1: Figure S2B). The growth analysis in liquid medium with glucose showed an extended lag period, with glucose consumption starting after $48 \mathrm{~h}$ of cultivation, which then decreased at a slow rate to around $40 \%$ at $168 \mathrm{~h}$ of cultivation (Additional file 1: Figure S2C). These data raised questions about the biological behavior of this basidiomycete growing on complex carbon sources in terms of protein expression and secretion, especially because of the presence of some non-canonical brownrot CAZymes such as $\mathrm{CBH}$ and AA2 peroxidase in the genome.

\section{Transcriptomic analysis reveals the early response of $L$. sulphureus ATCC $\mathbf{5 2 6 0 0}$ for the deconstruction of sugarcane bagasse}

A total of 10,015 transcripts were identified with at least one transcript per million (TPM), with 6920 sequences presenting statistical significance. Differential expression analysis revealed 1120 up- and 1455 downregulated genes, which included 96 CAZy transcripts and a set of 159 genes involved in redox metabolism (non-CAZy) (Additional file 1: Figure $\mathrm{S} 1 \mathrm{~B}$ and Additional file 2: Table S2). Among the CAZymes, 63 and 33 genes were up- and downregulated, respectively, with GHs comprising $60 \%$ of the upregulated genes. Five and 17 genes with predicted cellulolytic and hemicellulolytic functions, respectively, were identified among the upregulated CAZy transcripts, including glucanases (GH5, GH16, GH55, and GH71), $\beta$-glucosidases (GH1 and GH3), $\alpha$-xylosidase (GH31), $\alpha / \beta$-mannosidases (GH2 and GH47), and $\alpha$ - $/ \beta$-galactosidases (GH27, GH35, and GH71). In addition, several genes with predicted activity on starch (GH13 and GH31), chitin (GH18 and CE4), 
and pectin (GH28, GH78, and GH105) were upregulated, whereas transcripts predicted for xylan-active xylanase (GH30) and $\beta$-xylosidase (GH43) were downregulated.

Among the AAs, two AA1_1 laccases and one AA1_2 ferroxidase were upregulated; AA3 members such as the 11 members of the subfamily AA3_2 were downregulated, while one AA3_3 alcohol oxidase was upregulated. In addition, two AA7 glucooligosaccharide oxidases, one AA6 benzoquinone reductase, one AA9 LPMO, and one AA14 LPMO were upregulated (Fig. $3 \mathrm{a}$ and Additional file 2: Table S2).

A set of genes encoding non-CAZy enzymes and proteins with a predicted function in the oxidative mechanism and Fenton reaction were also regulated, corresponding to 159 transcripts, out of which 62 were up and 97 downregulated (Fig. 3a and Additional file 2: Table S2). The importance of this mechanism became clearer when the regulation of individual genes was analyzed, i.e., among the high upregulated transcripts (log2-fold change $\geq 2, n=43$ ), $67 \%$ were associated with oxidative mechanisms, including both AAs and nonCAZymes. The remaining CAZymes (33\%) were mostly hydrolases including miscellaneous hemicellulases (acting on glucan, mannan, galactan), amylases, pectinase, and chitinases. Remarkably, the top upregulated transcripts included a series of AA oxidoreductases belonging to the families AA3_3, AA1_2, AA6, and AA7, as well as non-CAZy oxidoreductases, dehydrogenases, cytochrome, and enzymes involved in LMW metabolism. In turn, transcripts of predicted cellulose- or xylan-active enzymes were absent (Fig. 3b).

\section{Proteins secreted by L. sulphureus ATCC 52600 during cultivation on pretreated plant biomass}

The exoproteomes of L. sulphureus ATCC 52600 cultivated on lignocellulosic biomass were analyzed by tandem mass spectrometry. A total of 3328 spectra were identified, accounting for 112 proteins. This set of proteins was composed of 42 CAZymes, 8 peptidases/ proteases, 8 non-CAZy oxidoreductases, 7 esterases, 5 dehydrogenases, 32 miscellaneous proteins/domains (denominated "others"), and 10 hypothetical proteins of unknown function (Additional file 1: Figure S1C and Additional file 2: Table S3). Of note, most of the proteins identified were predicted with SP.

GHs were predominant among the secreted CAZymes, accounting for $80 \%$ (34 members), followed by 6 AA members (Additional file 1: Figure S1C and Additional file 2: Table S3). Most of the GHs (62\%) corresponded to enzymes with predicted activity on hemicellulose, while 5 were cellulose-active GHs. In addition, GHs with predicted activity on pectin, starch, chitin, and trehalose,

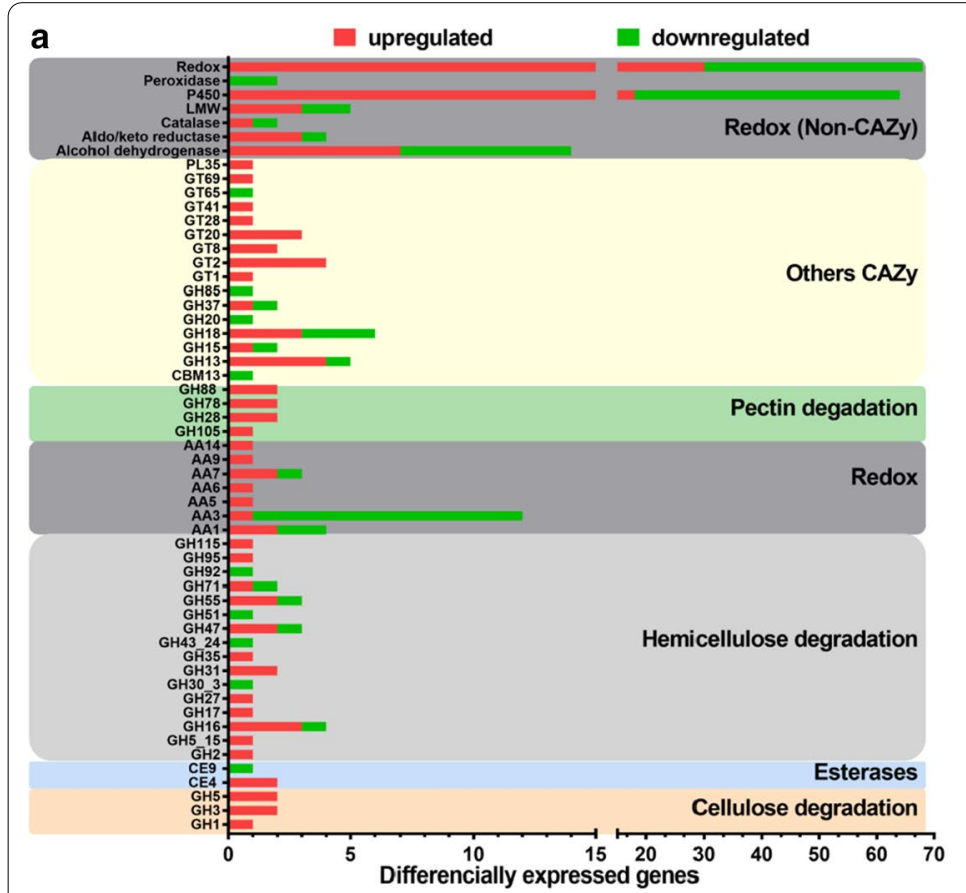

b

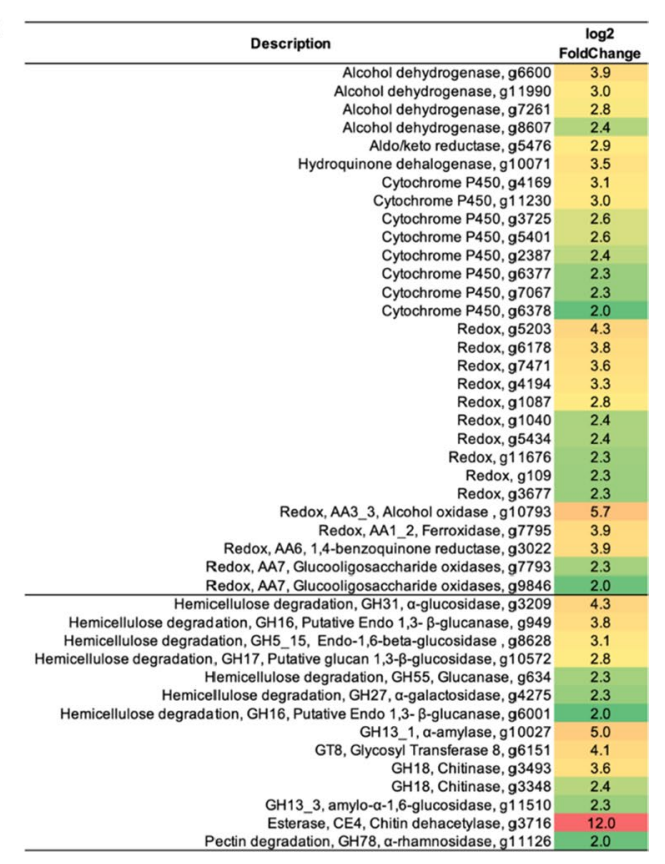

Fig. 3 Differentially expressed genes of L. sulphureus ATCC 52600 cultivated on sugarcane bagasse. a Up-and downregulated CAZyme genes and selected redox genes (non-CAZy) grouped according to their predicted function. $\mathbf{b}$ Highly expressed transcripts related to the $L$. sulphureus CAZy arsenal and oxidative mechanism ( $\log _{2}$-fold change $\geq 2$ ). CAZy classes: GH: glycoside hydrolases, CBM: carbohydrate-binding module, CE: carbohydrate esterase, PL: polysaccharide lyase, and AA: auxiliary activities 
as well as one PL35 alginate lyase were also secreted (Additional file 2: Table S3). Overrepresented GH families corresponded to GH18 with predicted chitinolytic activity (g5150, g834, and g10854), and GH3 represented by $\beta$-glucosidases (g2032 and g11777) and $\beta$-xylosidase (g7390). The secreted AAs array consisted of AA3 aryl alcohol oxidases (g5677, g5675, g5206, and g10342), AA5 glyoxal oxidase (g4370), and AA7 glucooligosaccharide oxidase (g9758) (Fig. 4a).

The highest number of CAZymes was identified in the secretome produced on SCB (40 proteins), followed by $33,30,27$, and 16 proteins identified on Eucalyptus, Avicel, SCS, and glucose, respectively. Differences in the CAZyme arsenal produced by L. sulphureus ATCC 52600 for lignocellulose degradation became evident when comparing the secretomes (Fig. 4b and Additional file 2: Table S3). A total of 16 CAZymes were secreted in all conditions, indicating constitutive secretion. The secretome produced on SCB showed the highest number of upregulated CAZymes, comprising 16 hits, out of which 10 were exclusively found in this condition. These hits corresponded to exo-type enzymes mainly related to hemicellulose degradation such as GH3 $\beta$-xylosidase (g7390), GH35 $\beta$-galactosidase (g11423), and GH47 $\alpha$-mannosidase (g10983), along with GH3 $\beta$-glucosidase (g11777) and AA7 oxidoreductase (g9758). Moreover, the secretomes produced on SCB and SCS showed common upregulation of GH3 (g2032), AA3_2 (g5675), and GH20 (g8819). Interestingly, some enzymes with basal constitutive secretion in the secretome produced on glucose such as GH7 CBH (g8442), GH92 $\alpha$-1,2-mannosidase (g9634), and GH18 chitinase (g834) were upregulated on Avicel. Additionally, one xylanase (g4476) was upregulated on all polymeric substrates, and one AA3_2 aryl alcohol oxidase (g10342) was exclusively upregulated on SCS. Despite the high number of proteins secreted on Eucalyptus, only one $\beta$-L-arabinofuranosidase (g6508) was upregulated in this condition as well as on SCB. Another remarkable characteristic was the absence of AAs in the secretome produced on Avicel. Finally, some proteins among the 17 non-CAZy classified as "others" were upregulated at least in one condition, mostly on SCB. Prominent among them were galactose oxidase (g7548) and another oxidoreductase (g9473), both showing upregulation on Avicel, SCB, and Eucalyptus (Additional file 2: Table S3).

\section{Performance of the $L$. sulphureus ATCC 52600 secretome on biomass conversion}

Enzymatic activity profiles were evaluated on the $L$. sulphureus ATCC 52600 secretomes and most of the identified activities were found at higher levels on SCB. Activities were detected on arabinoxylan, $\beta$-glucan, starch, and xylan from beechwood (Additional file 1: Figure S3), corroborating the enzymes identified in the
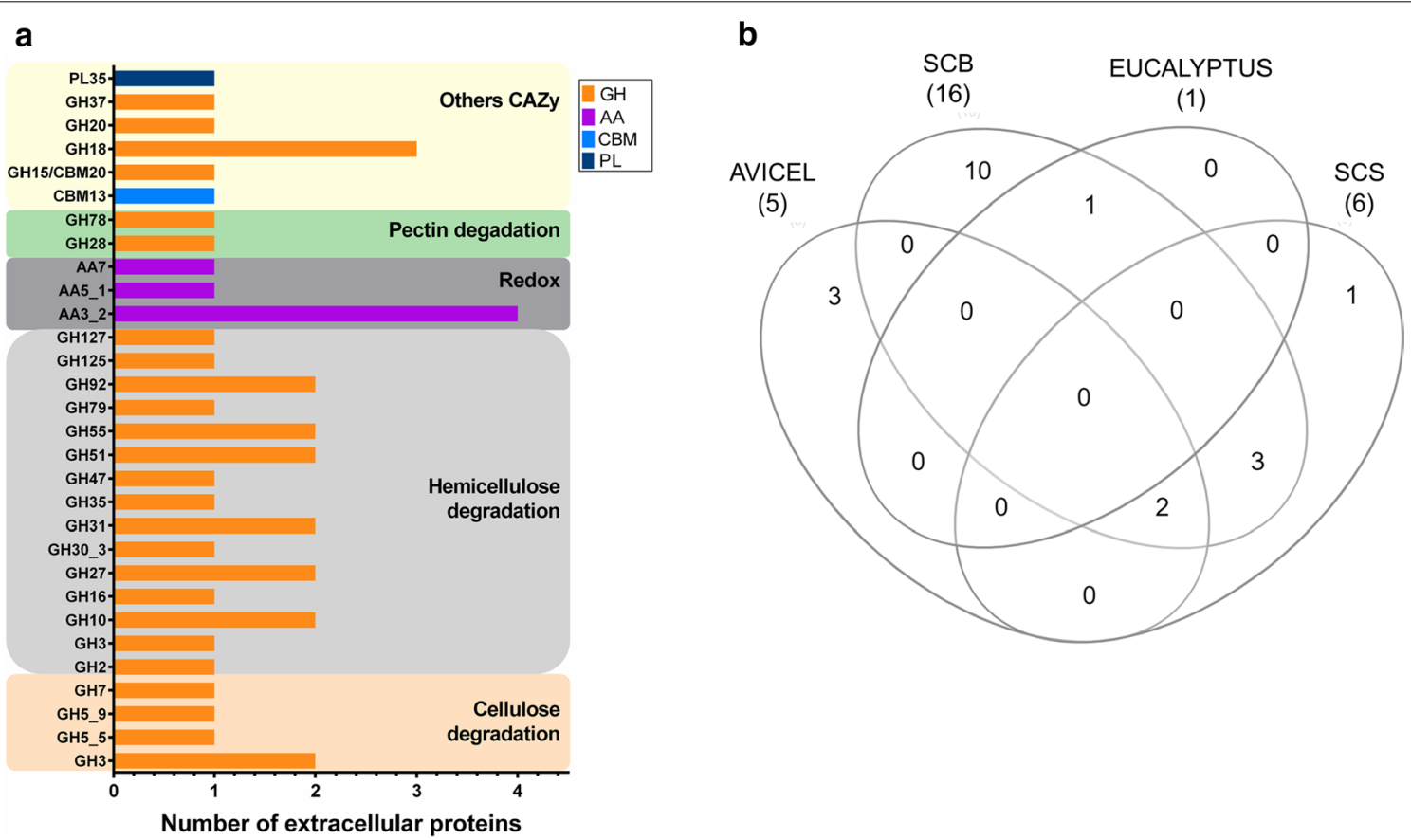

Fig. 4 Overview of CAZymes identified in the L. sulphureus ATCC 52600 secretomes. a CAZy classes: GH: glycoside hydrolases, CBM: carbohydrate-binding module, CE: carbohydrate esterase, PL: polysaccharide lyase, and AA: auxiliary activities. b Venn diagrams grouping upregulated CAZymes relative to glucose. SCB sugarcane bagasse, Eucalyptus: Eucalyptus grandis residue, SCS sugarcane straw 
secretomes (Additional file 2: Table S3). The secretome produced on SCB was then applied for supplementing commercial enzymatic cocktails in the saccharification of pretreated lignocellulosic biomass such as sugarcane straw (grass) and pine (softwood).

Glucan conversion obtained with sugarcane straw ranged from 40 to $55 \%$ by using the commercial cocktail at $85 \%$ or $100 \%$ enzyme load, respectively. Replacing $15 \%$ of the commercial cocktail with the secretome produced on SCB increased the glucan conversion by 7\% (Fig. 5a). In turn, no differences were observed in the xylan conversion, which was around 30\% (Fig. 5b). Saccharification of pine lignocellulose was noticeably less efficient for both glucan (12\%) and xylan (around 8\%) conversion, and unresponsive to the enzymatic supplementation with the L. sulphureus secretome.

\section{Discussion}

\section{L. sulphureus ATCC 52600 genome does not resemble} typical brown-rot fungi

Genomic sequencing of filamentous fungi followed by transcriptomic and proteomic approaches has been widely employed to understand the strategies of microorganisms to degrade plant biomass [23-29]. Overall, the L. sulphureus ATCC 52600 genome revealed only subtle differences compared to the previously sequenced
L. sulphureus var. sulphureus v1.0 [22], indicating that the strains might have undergone some changes in their ecological niches to shape their genomes to the environmental conditions. Our phylogenetic analysis, providing high resolution on the evolutionary history of organisms by considering whole-genome information [29], complements the previous phylogeny of the order Polyporales [10]. The phylogenetic tree (Fig. 1) strongly supports monophyletic clades for the families within the order Polyporales. L. sulphureus ATCC 52600 clusters with $L$. sulphureus var. sulphureus v1.0 and W. cocos giving further support to the existence of the family Laetiporaceae Jülich, as previously proposed [10] and currently present in Mycoguide, but retrieved as an invalid name in MycoBank and Index Fungorum.

The genomic CAZyme content in both $L$. sulphureus strains and the closely related brown-rot Polyporales shows a typical number of GHs, CEs, PLs, and GTs compared to $W$. cocos, P. placenta and $F$. radiculosa, whereas a lower number of CAZymes, particularly GHs, were observed in comparison with Fomitopsis pinicola (Fomitopsidaceae). In turn, L. sulphureus ATCC 52600 shows a higher AA content than in the other genomes [9]. Additionally, the genome presents several similarities with other brown-rot genomes associated with evolutionary reductions and losses in key enzymes involved in biomass
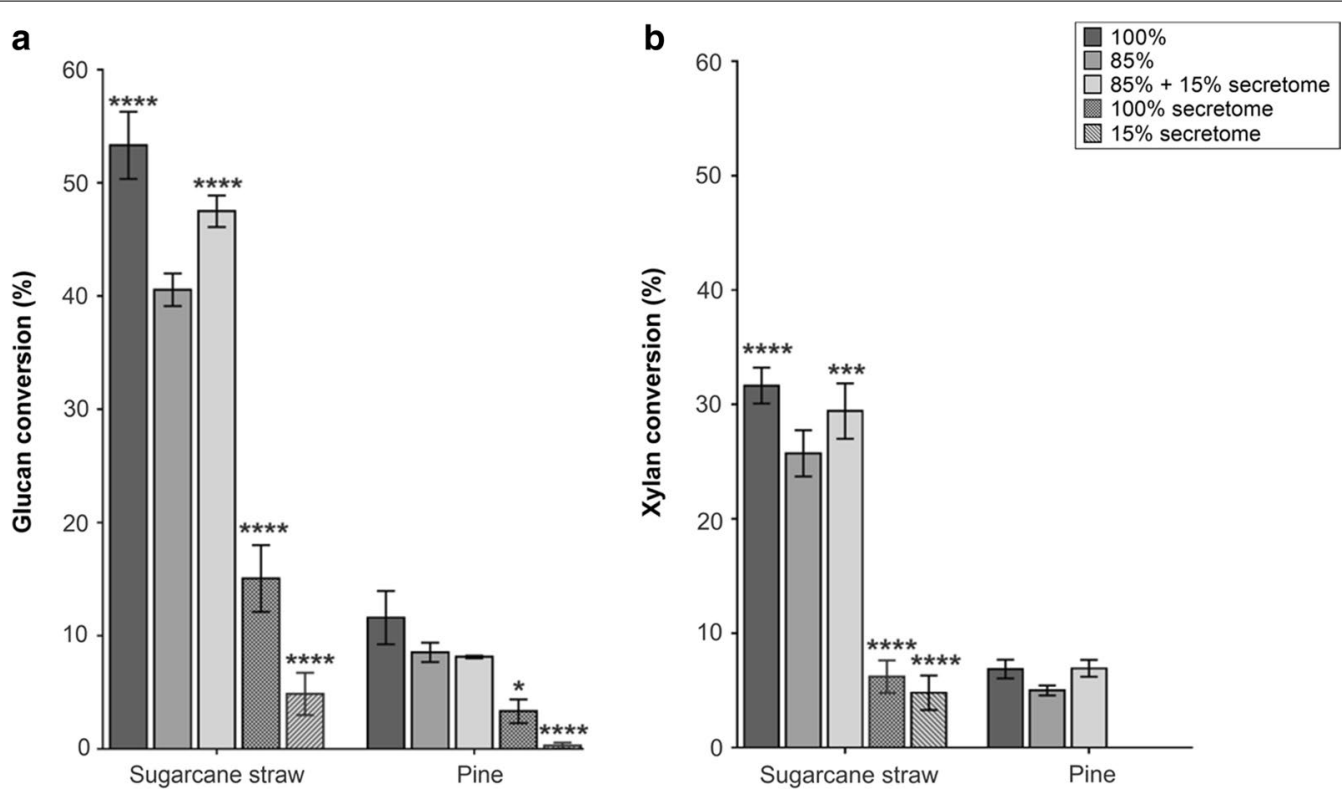

Fig. 5 Saccharification of hydrothermally pretreated sugarcane straw and pine. $\mathbf{a}$ Glucan and $\mathbf{b}$ xylan enzymatic conversion. The reaction was performed with a mixture of Celluclast ${ }^{\circledR}$ : glucosidase from Aspergillus niger (5:1 W/W) supplemented with L. sulphureus ATCC 52600 secretome produced on SCB. Total protein load corresponds to $15 \mathrm{FPU} / \mathrm{g}$ of substrate (100\%). Reactions containing $2 \%(\mathrm{w} / \mathrm{v}$ ) solids load in $50 \mathrm{mM}$ sodium acetate $\mathrm{pH} 5.0$ were incubated for $48 \mathrm{~h}$ at $50^{\circ} \mathrm{C}$. Data correspond to mean values and standard deviations of four triplicates. Significance was analyzed using two-way ANOVA with Tukey's test relative to the reference reaction "85\% Celluclast" (95\% confidence interval) and is indicated as follows: ${ }^{*} p<0.05,{ }^{* *} p<0.01,{ }^{* * *} p<0.001$ 
breakdown, especially cellulases and lignin-modifying enzymes [3]. Accordingly, it presents a reduced number of genes coding CAZymes from the families GH1, GH3, GH5, GH7, GH10, AA9, and CE1 along with the absence of GH6, GH11, AA3_1, CBM1, and CE15 (Additional file 2: Table S1).

Considering these reductions or absences, other enzymes may also be necessary to achieve an effective breakdown of cellulose and hemicellulose, such as the AA9 and AA14 LPMOs. AA9s perform oxidative cleavage on cellulose and other glucans with great importance in lignocellulose degradation [30], presenting an average number of 3 genes in Polyporales genomes $[3,26]$. The recently established family AA14 also groups LPMOs that are widespread in fungi. Within the order Polyporales, there are 4.5 and 2.5 AA14 coding genes on average in white and brown-rot genomes, respectively [31]. This reduction pattern can also be observed for other gene reductions associated with the brown-rot lifestyle evolution. One characterized AA14 member from the whiterot Pycnoporus coccineus presents oxidative activity on xylans of xylan-coated cellulose fibers [31], and shares $48.8 \%$ identity with the L. sulphureus ATCC 52600 AA14 LPMO (Additional file 1: Figure S4).

Regarding the enzymes involved in the oxidative mechanism, AA3_1 CDHs are absent in L. sulphureus, as verified in P. placenta, W. cocos, and F. pinicola [32]. In turn, a large number of genes coding for AA3_2 (aryl alcohol oxidase and glucose 1-oxidase) and AA3_3 (alcohol oxidase) was identified, and the products $\mathrm{H}_{2} \mathrm{O}_{2}$ (reduction of oxygen by oxidases) and hydroquinones (reduction of quinones) can support other enzymes that are important for lignocellulose deconstruction [33]. Similarly, AA5_1 glyoxal oxidases and AA6 benzoquinone reductase, which are also involved in Fenton reagents generation [34-36], were identified (Additional file 2: Table S1). Notably, the absence of $\mathrm{CDH}$ may also suggest the presence of other redox partners for the AA9 and AA14 LPMOs, such as AA3_2 flavoenzymes [37] and GMC oxidoreductases, among others [38], or the peroxide production might be driving LPMOs reaction [39].

The L. sulphureus genome also revealed some distinctions in the lignocellulolytic repertoire. For example, the well-known lack of cellulases in brown-rot fungi is generally attributed to a reduced number of GH6/GH7 CBHs $[32,40,41]$, which are absent in brown-rot Polyporales [42]. Our sequencing, however, identified one putative GH7 CBH (g8442) in the L. sulphureus ATCC 52600 genome, in accordance with a $\mathrm{GH} 7 \mathrm{CBH}$ previously identified in the secretome of L. sulphureus growing on $\mathrm{CMC}$ [20]. Sequence analysis shows these enzymes sharing more than $90 \%$ identity, and the phylogeny using predicted and characterized fungal CBHs reveals 65\% similarity with other fungal CBHs (Additional file 1: Figure S5). Additionally, analysis of 42 fungal genomes indicates that brown rots generally have a reduced number of GH45, in a 3:1 ratio in comparison with white rots [9]. Our initial search parameters identified one putative GH45 (g10751), coinciding with a GH45 (ID 174,393) previously identified in the L. sulphureus secretome [20]. These sequences share $92.5 \%$ identity; having an expansin domain predicted by InterPro v.78.1 [43], despite the previous classification as GH45 class C [20]. Expansins are closely related to GH45 endoglucanases and have been widely found in brown-rot strains [9], playing an important function in reducing biomass recalcitrance, consequently increasing the deconstruction of lignocellulose in synergism with cellulases [44].

Lignin degradation and the importance of different lignin-active enzymes in brown rots is a matter of debate, but it is widely recognized that brown rots present a reduced number of laccases and absence of PODs class II in comparison with white-rot strains $[8,45,46]$. L. sulphureus ATCC 52600 has AA1_1 and AA1_3 laccases, similar to F. pinicola, P. placenta, and W. cocos [47]. Additionally, 13 predicted PODs were identified in the L. sulphureus ATCC 52600 genome, and two of them with predicted AA2 domain. InterPro annotation classified one of them as an intracellular POD class I, while the other (g11846) was classified as a fungal ligninase/POD class II with a predicted SP. BLAST search retrieved $87 \%$ and $66 \%$ identity with PODs class II from L. sulphureus var. sulphureus v1.0 and $W$. cocos MD-104SS10 v1.0, respectively. POD class II has been reported as a single copy in P. placenta, W. cocos and F. pinicola genomes [32], and the P. placenta peroxidase (Ppl44056) was classified as a basal peroxidase, not closely related to LiP and $\mathrm{MnP}$ [48]. Laccases in Polyporales are multigenic [49] and have been characterized as functional enzymes in $P$. placenta and $F$. pinicola [50-52], playing a role in wood decay performed by P. placenta [50]. Significant lignolysis has been observed in Gloeophyllum trabeum (Gloeophyllales) and P. placenta without considering the involvement of PODs class II $[6,53]$. Nevertheless, the biological importance or the precise role of these PODs II found specifically in L. sulphureus and other closely related brown rots are uncertain since these enzymes have not been characterized to date.

\section{Insights into the L. sulphureus ATCC 52600 biomass deconstruction mechanism}

Several omics studies analyzing brown-rot fungi with significant taxonomic and niche distances such as W. cocos, F. radiculosa, P. placenta, G. trabeum, and Serpula lacrymans (Boletales), cultivated in different conditions show the common presence of a two-step mechanism involved 
in biomass deconstruction $[8,25,48,54-60]$. The initial oxidoreductive step is estimated to persist for $48 \mathrm{~h}$ [8], which can be correlated with both the observed slow growth of $P$. placenta in cellulose and spruce [56] and the L. sulphureus growth and glucose consumption in liquid medium (Additional file 1: Figure S2C).

The transcriptome data of a short cultivation period reveal a series of upregulated genes related to the oxidative mechanism, probably induced by the recalcitrance of the non-pretreated sugarcane bagasse (Fig. 3 and Additional file 2: Table S2). The most upregulated transcripts include alcohol dehydrogenase, cytochrome P450, aldo/ keto reductases, and redox genes involved in the generation of hydrogen peroxide, while hydroquinone dehalogenase is involved in hydroquinone production that initiates Fenton reaction by carrying $\mathrm{Fe}^{3+}[61]$. Moreover, the presence of AA6 quinone reductases suggests that this enzyme takes part in the quinone redox cycle supporting Fenton chemistry, as previously observed in $P$. placenta [48], while also playing a role in the detoxification process [5]. Such observations are consistent with a biodegradative role of Fenton chemistry occurring during early cultivation of $L$. sulphureus on SCB, as verified in other brown-rot transcriptomes $[9,62,63]$.

Regarding CAZymes (Fig. 3a and Additional file 2: Table S2), previous brown-rot transcriptomic studies similarly revealed a small set of cellulases and hemicellulases with predicted activity on glucans and mannans $[8,48]$. The upregulation of some cellulases and hemicellulases supports the existence of inducing mechanisms, which may depend on substrate exposure and availability but operating differently than reported for white-rot basidiomycetes or ascomycetes [56]. Additionally, the upregulation of two AA1 laccases indicates an ability to partially oxidize lignin. On the other hand, two other AA1 laccases, as well as two non-CAZy peroxidases were downregulated, so the importance of ligninases for this fungus remains unclear (Fig. $3 \mathrm{a}$ and Additional file 2: Table S2). Transcripts of AA9 and AA14 LPMOs were upregulated, but not secreted, corroborating the concept of LPMOs being produced by fungi during early biomass degradation $[62,64,65]$. Our data indicate that L. sulphureus adopts mechanisms to integrate enzymatic and non-enzymatic systems at initial stages of brown-rot decay, as previously reported in G. trabeum [65]. Of note, the biological importance of LPMOs for brown-rot fungi remains unclear since their secretion has only been identified in G. trabeum growing on lignocellulose [48].

Furthermore, the growing of L. sulphureus on pectin and the upregulation of pectinases transcripts (Additional file 1: Figure S2A and B and Additional file 2: Table S2) support the mechanism in which pectin degradation also occurs in the early stage of degradation as previously observed in P. placenta and G. trabeum. Pectin removal by pectinases may facilitate the access of other enzymes to the plant cell wall components $[8,56,57]$.

In contrast to the transcriptome, our secretome data (7-day cultivation) represents a late hydrolytic decay profile [56], which is supported by the absence of AAs in the secretome produced on Avicel. A core set of constitutive CAZymes was identified, comprising some GHs with predicted activity on cellulose and a wide diversity of GHs acting on glucans, xylan, mannans, trehalose, starch, and chitin (Additional file 2: Table S3). Apart from the xylan-active enzymes, the hemicellulase set is very similar to the profile observed in the transcriptome. This complete set of hemicellulases found in brown rots [56] allows the fungus to obtain energy sources from diverse substrates, providing an increase in survival capability under different environmental conditions.

Additionally, regulatory mechanisms may take place after the sensing and transport of inducers, resulting in the secretion of a repertoire of CAZymes targeted to substrate degradation. In that sense, differences in the enzymatic arsenal can be observed in the secretomes of L. sulphureus produced on grass and wood-derived substrates, which typically present different compositions $[66,67]$. The secretome produced on SCB showed the highest diversity of upregulated proteins probably due to substrate recalcitrance and pretreatment characteristics $[68,69]$.

Endoglucanases are poorly secreted by L. sulphureus, apparently playing a minor role in cellulose degradation, despite the importance of processive endoglucanases in brown rots [70]. Two GH3 $\beta$-glucosidases are upregulated on $\mathrm{SCB}$ and notably the $\mathrm{GH} 7 \mathrm{CBH}$ undergoes upregulation exclusively on Avicel. These data, in addition to the basal secretion of some CAZymes commonly found in all substrates, show that $\mathrm{CBH}$ is inducible and it is not under carbon catabolite repression, as verified for the endoglucanase from G. trabeum [71] or cellulases from P. placenta [56]. However, the gene encoding GH7 $\mathrm{CBH}$ is not differentially expressed (transcriptomeearly stage), and the secretion of endoglucanases and $\beta$-glucosidases as well as oxidative agents, may compensate for that low expression in early stages $[4,6]$.

In addition to the constitutive hemicellulases, a diversity of enzymes acting on glucan and mannan (mannosidases and $\alpha$-galactosidases) were upregulated at both early and late response to biomass degradation (Additional file 2: Tables S2 and S3) corroborating a natural preference of brown rots for softwoods $[1,3,7$, 59]. There is evidence that hemicellulose loss progresses faster than cellulose loss in coniferous wood decay performed by G. trabeum, F. pinicola, W. cocos and L. sulphureus [72, 73]. Additionally, our secretome data show 
that L. sulphureus targets hemicellulose as part of the hydrolytic late response. Several enzymes active on xylan, the main hemicellulose in grasses [74], were secreted by L. sulphureus, i.e., one GH10 xylanase is upregulated on Avicel and SCB, while the production of another GH10 xylanase is constitutive. Also, one $\beta$-xylosidase is upregulated on SCB, while two $\alpha$ - $\mathrm{L}$-arabinofuranosidases are widely secreted on the polymeric substrates (Additional file 2: Table S3). Moreover, transcripts of other arabinoxylan-degrading enzymes do not show early upregulation; rather, one GH30 xylanase and one GH51 arabinofuranosidase are downregulated (Additional file 2: Table S2). This result shows that L. sulphureus can adapt the metabolism to the degradation of a grass substrate, despite other brown rots from the Antrodia clade have been reported to be inefficient in the degradation of corn stalk [75].

Despite the ability of $L$. sulphureus to grow on xylan and galactomannan (Additional file 1: Figure S2A and B), in addition to the presence of some cellulases and several hemicellulases in the late-response secretome (Additional file 2: Table S3), biomass conversion was low, especially for softwood (Fig. 5). The lack of mannanases in the commercial cocktail [76] and the SCB secretome may be a possible explanation for the ineffective degradation of the pine biomass. Indeed, brown-rot fungi are known to grow and modify pine and other softwoods [73, 77, 78]; however, softwood is among the most recalcitrant lignocellulosic substrates for enzymatic processes, requiring severe pretreatment conditions as well as higher enzyme doses than hardwood or grass substrates [79]. Lignin content, larger amounts of extractive components, and smaller pore size are additional characteristics that may be further contributing to the poor degradation of this lignocellulose [80].

In Fig. 6, an overview of the L. sulphureus strategies for biomass deconstruction is proposed based on our multi-omics data. Our results are consistent with a temporal two-step oxidative-hydrolytic mechanism for the degradation of lignocellulose, while also demonstrating that this fungus does not resemble typical brownrot fungi in many aspects, thus contributing to the weak dichotomy between white- and brown-rot strains, as previously proposed [26]. Additional data applying biological approaches such as gene deletion and analysis of wood decay, as well as biochemical characterization of the enzymes would contribute to further address this question.

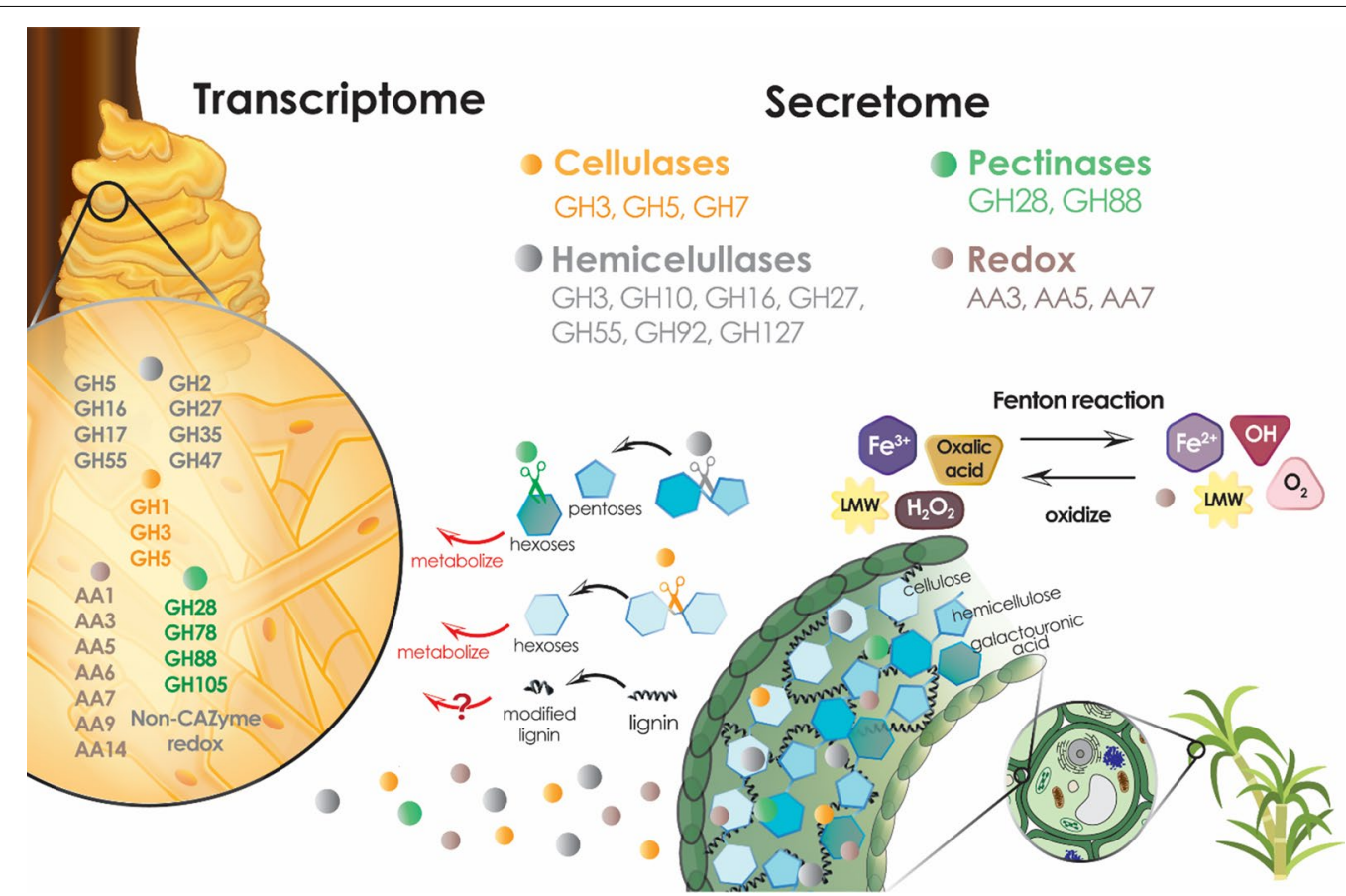

Fig. 6 Biomass degradation mechanism from L. sulphureus ATCC 52600. Multi-omics analysis showing the range of CAZymes induced in response to sugarcane lignocellulose. The scheme represents the main CAZymes found in the transcriptome (in the basidium stem) and secretome analysis responsible for lignocellulose deconstruction and lignin modification by the oxidative mechanism, involving CAZymes, low-molecular-weight (LMW) compounds, and Fenton reaction. In parallel, monomers released from holocellulose are metabolized, unlike lignin, which remains partially degraded 


\section{Conclusions}

Genome sequencing and analysis of expression and secretion patterns contributed to elucidate the mechanism involved in lignocellulose degradation by $L$. sulphureus ATCC 52600. In many aspects, this brown-rot fungus presents similarities with other model brown rots, while not resembling typical brown rots, especially due to the notable presence of cellobiohydrolase and POD class II. The transcriptomic analysis using highly recalcitrant biomass at a short cultivation period demonstrated the presence of early oxidative response, as well as other hallmarks of an early response such as the upregulation of pectinases and oxidative enzymes, including LPMOs. The late response was evaluated by proteomic analysis of secretomes produced on cellulose, and lignocellulose from grass (sugarcane bagasse and straw), and hardwood (Eucalyptus). Overall, the secretome profiles showed a common set of CAZymes in different conditions, with only subtle differences in the secretion of specific enzymes. Some cellulases displayed constitutive secretion while a more complex regulatory mechanism may be occurring for enzymes acting on xylan degradation. Another remarkable characteristic is the absence of AAs in the degradation of crystalline cellulose, but not in the degradation of lignocellulosic substrates.

\section{Methods}

\section{Strain maintenance}

L. sulphureus ATCC 52600 was purchased from Fundação André Tosello (CCT 4694). The strain was routinely maintained on solid media composed of $20 \mathrm{~g} / \mathrm{L}$ malt extract and $2 \mathrm{~g} / \mathrm{L}$ yeast extract and incubated for $7-10$ days at $30{ }^{\circ} \mathrm{C}$.

\section{DNA extraction and sequencing}

DNA extraction from mycelia was performed using phenol-chloroform, followed by RNAse treatment. High-quality DNA was obtained using the DNeasy Kit (Qiagen). Three Illumina libraries were constructed, a paired-end library with a 300-bp insert and two mate-pair libraries with $5-7$ and $8-11 \mathrm{~kb}$, according to the manufacturer's instructions. The libraries were sequenced on an Illumina HiSEq 2500 platform.

\section{Genome assembly and annotation}

Paired-end and mate-pair reads $(2 \times 100 \mathrm{pb})$ were filtered by quality and presence of adaptors using Trimmomatic v0.32 [81] and NextClip [82] default parameters, respectively. The genome was de novo assembled using Velvet v.1.2.10 [83] with $\mathrm{kmer}=55$. The resulting assembly was scaffolded by SSPACE v3.0 [84] and the mate-pair reads, and further refined by Pilon version 1.16 [85]. The completeness of the genome was assessed using Benchmarking Universal Single-Copy Orthologs (Busco) [86] and the prediction was performed using BRAKER1 [87], which applies GeneMart-ET and AUGUSTUS along with RNA-seq alignments for gene prediction. Predicted protein sequences were functionally annotated by searching for homologous sequences in the SwissProt [88], EggNOG [89], and Pfam [90] databases. Signal peptides (SP), transmembrane regions, and ribosomal genes were predicted using SignalP v.4.0 [91], TMHMM [92], and ITSx using fungal models, respectively. Carbohydrate transporters were identified and classified according to the PFAM 00,083.21 [29] and enzymes associated with LMW metabolism were classified using Gene Ontology (http://geneontology.org). Comprehensive analysis of CAZymes was carried out using HMM-based dbCAN v.8 [93], HMMER (E-Value $<1 \mathrm{e}-15$, coverage $>0.35$ ), DIAMOND (E-Value $<1 \mathrm{e}-102$ ), and Hotpep (Frequency $>2.6$, Hits $>6)$.

\section{Phylogenetic analysis}

The phylogenomic relationship of L. sulphureus ATCC 52600 and its closest described relatives of the family Laetiporaceae was determined based on orthologs singlecopy genes using FastOrtho tool (https://github.com/ olsonanl/FastOrtho). The protein sequences of each 601 single-copy orthologous genes present in 31 basidiomycete genomes closely related to the family Laetiporaceae and L. sulphureus ATCC 52600 were aligned by Mafft v.7.299 [94] and the resulting individual alignments were concatenated to create a supermatrix using FASconCATG v.1.02 [95]. Evolutionary distance was inferred using maximum likelihood with RAxML v.8.2.0 [96], implementing PROTGAMMAWAG model and performing 1000 bootstrap replicates to evaluate the reliability of the reconstructed phylogenetic tree.

\section{Cultivation conditions for transcriptome analysis}

Pre-inoculum, consisting of 15 discs (8 mm diameter) of L. sulphureus ATCC 52600 pre-cultivated on agar plates, was inoculated into $100 \mathrm{~mL}$ of liquid medium and incubated under $180 \mathrm{rpm}$ for 7 days at $30{ }^{\circ} \mathrm{C}$. Mycelia were then filtered and washed with water and transferred to liquid medium containing $1.0 \mathrm{~g}$ of in natura sugarcane bagasse and $100 \mathrm{~mL}$ of medium pH 7.0 composed of $6 \mathrm{~g} / \mathrm{L}\left(\mathrm{NH}_{4}\right)_{2} \mathrm{SO}_{4}, 1 \mathrm{~g} / \mathrm{L} \mathrm{KH}_{2} \mathrm{PO}_{4}, 1 \mathrm{~g} / \mathrm{L} \mathrm{KCl}$, and $1 \mathrm{~g} / \mathrm{L}$ $\mathrm{MgSO}_{4}$. Cultivation was performed under $180 \mathrm{rpm}$ for $24 \mathrm{~h}$ at $30{ }^{\circ} \mathrm{C}$. Mycelia and substrate mixtures were collected by filtration, washed with sterile water, manually dried in filter paper, and stored at $-80{ }^{\circ} \mathrm{C}$ before RNA extraction. Mycelium from the pre-inoculum was used as a standard before induction $\left(\mathrm{T}_{0}\right)$. 


\section{RNA extraction and sequencing}

The mycelium was ground with liquid nitrogen and total RNA extraction was performed with mirVana ${ }^{\mathrm{TM}}$ Total Isolation Kit (Thermo Fisher), according to the manufacturer's instructions. The resulting solution was treated with DNAse (DNA-Free RNA Kit, Zymo Research) and purified with RNeasy Kit (Qiagen), and quality was verified using RNAnano Bioanalyzer 2100 chip (Agilent). cDNA libraries were prepared according to the manufacturer's instructions and sequenced on the Illumina HiSEq 2500 platform.

\section{Bioinformatics analysis of RNA-seq data}

Reads were processed as described previously for the genome libraries and evaluation and filtration of the rRNAs were performed using SortmeRNA. The filtered data were mapped into the $L$. sulphureus ATCC 52600 reference genome sequenced in this work using the Tophat2 algorithm [97]. Differential gene expression analysis was based on counting data and performed with the Bioconductor DESeq2 package [98] using the $\mathrm{R}$ platform, by paired comparisons against the control condition. Transcripts showing differential expression ( $\log 2-$ fold change $\geq 1$ and $\leq-1$ ) relative to the non-induced condition (T0) were determined by applying $p \leq 0.05$ as the threshold.

\section{Carbohydrate metabolism and glucose consumption}

Mycelia discs were excised from the border of the colony growing on potato dextrose agar plates and transferred to the center of minimal medium agar plates [99] supplemented with $1 \%(\mathrm{w} / \mathrm{v})$ of the following substrates: glucose, arabinose, galacturonic acid, xylose, lactose, cellobiose, galactose, xylan from beechwood, pectin from citrus, and galactomannan from carob. Cultivation was performed in six replicates for 7 days at $30{ }^{\circ} \mathrm{C}$, and growth rates were estimated from the daily measurement of the colony area using the software Image J 1.52a [100]. For cultivation in liquid medium, 15 mycelial discs were transferred into $250-\mathrm{mL}$ Erlenmeyer flasks containing $100 \mathrm{~mL}$ of liquid minimal medium $\mathrm{pH} 5.5$ supplemented with $1 \%(\mathrm{w} / \mathrm{v})$ glucose for 7 days under static conditions at $30{ }^{\circ} \mathrm{C}$. Cultivation was performed in triplicate and samples were taken at $6,12,24,48,72,96$, and $120 \mathrm{~h}$ of cultivation. Residual glucose was measured by high-performance liquid chromatography (HPLC), as described below.

\section{Cultivation conditions for proteomic analysis Pre-inoculum}

L. sulphureus ATCC 52600 was grown on potato dextrose agar plates pH 5.5 at $25^{\circ} \mathrm{C}$. After 7 days of cultivation, 15 mycelium discs ( $8 \mathrm{~mm}$ diameter) were excised from the colony border and transferred to 250-mL Erlenmeyer flasks containing $50 \mathrm{~mL}$ of liquid medium composed of $0.5 \mathrm{~g} / \mathrm{L} \mathrm{NH}_{4} \mathrm{CH}_{3} \mathrm{CO}_{2}, 0.5 \mathrm{~g} / \mathrm{L} \mathrm{NaNO}_{3}, 0.5 \mathrm{~g} / \mathrm{L} \mathrm{MgSO}_{4}$, $0.2 \mathrm{~g} / \mathrm{L} \mathrm{Na}_{2} \mathrm{HPO}_{4}, 0.8 \mathrm{~g} / \mathrm{L} \mathrm{KH}_{2} \mathrm{PO}_{4}, 4.0 \mathrm{~g} / \mathrm{L}$ yeast extract, and $10.0 \mathrm{~g} / \mathrm{L}$ glucose. The pre-inoculum was incubated for 21 days under static conditions at $30^{\circ} \mathrm{C}$.

\section{Cultivation}

Pre-grown mycelia were removed by filtration, washed with distilled water, transferred to a 50-mL conical tube, and manually macerated with $2 \mathrm{~g}$ of glass beads. The macerated mycelia were then transferred to $250-\mathrm{mL}$ Erlenmeyer flasks containing $50 \mathrm{~mL}$ minimal medium pH 5.5 supplemented with $1 \%(\mathrm{w} / \mathrm{v})$ steam-exploded sugarcane bagasse (SCB), steam-exploded sugarcane straw (SCS), steam-exploded Eucalyptus residue (Eucalyptus grandis), Avicel ${ }^{\circledR} \mathrm{PH}-101$ (Sigma), and glucose. Cultivation was performed in triplicate under static conditions for 7 days at $30{ }^{\circ} \mathrm{C}$.

\section{Mass spectrometry and data analysis}

Cultivation supernatants (secretomes) were filtered with Miracloth (Millipore), centrifuged $(13,000 \mathrm{~g}, 20 \mathrm{~min}$, $4{ }^{\circ} \mathrm{C}$ ), and concentrated using 10-kDa cut-off Amicon Centrifugal Filter Units (Millipore). Protein concentration was measured with the Pierce BCA Protein Assay kit (Thermo Scientific) using BSA as standard. Secretomes $(20 \mu \mathrm{g})$ partially resolved on $12 \%$ SDS-PAGE [101] were excised, reduced, and digested with $20 \mathrm{mg} / \mathrm{ml}$ trypsin (Promega) [102]. After extraction, samples were dried under vacuum and peptide mixtures were analyzed in LTQ Velos Orbitrap-activated, as described elsewhere [103].

Spectra data were annotated based on the L. sulphureus ATCC 52600 genome. The adjusted conditions to validate protein identification were protein probability thresholds higher than $99 \%$ and at least 2 different peptides identifying a protein, each with $95 \%$ certainty. Once the parameters were defined, a $0.0 \%$ false discovery rate (FDR) was generated and spectrum count data were analyzed in a semi-quantitative method. Spectra counts are equivalent to the total number of standard spectra assigned to each protein and are commonly used to determine relative abundance [104]. As the spectra counting methodology was used for analysis, FDR was designated as one of the parameters to determine the reliability of the experimental data. FDR was defined as the expected correspondent percentage of each peptide spectrum [105]. Initially, a score was assigned to each peptide (primary analysis) performed with Mascot Distiller software. Subsequently, Mascot 
data were analyzed by Scaffold 4 Proteomic software attributing the number of spectra to the abundance and FDR to the reliability of the results. By using average spectra outputs from Scaffold 4, differentially secreted proteins were identified according to their spectra counting and quantitative values were applied to normalize the counts. The statistical analysis of the spectra was performed by the t-test $(p \leq 0.05)$ and fold change by category, using data from cultivation with glucose as standard.

$\mathrm{GO}$ terms were analyzed and identified in the topGO platform (https://bioconductor.org/packages/release/ bioc/html/topGO.html) using the following tools: basic local alignment search (BLAST) (https://blast.ncbi.nlm. nih.gov/Blast.cgi), PFAM (https://pfam.xfam.org/), and MEROPS (https://merops.sanger.ac.uk/). Parameters used to run BLASTp were: E-value $\leq 40$, identity $\geq 40 \%$, and consultation coverage $\geq 80 \%$. Classification of CAZymes and carbohydrate-binding modules (CBM) was performed on dbCAN v.8 (www.csbl.bmb.uga.edu/ $\mathrm{dbCAN}$ ). The presence of at least three representative members was established to define a classification group. Prediction of signal peptide (SP) and non-classical protein secretion were verified using SignalP 4.1 (www.cbs. dtu.dk/services/SignalP) and SecretomeP 2.0 (www.cbs. dtu.dk/services/SecretomeP/), respectively.

\section{Activity on different substrates}

Enzymatic assays were performed using $50 \mu \mathrm{l}$ of the following substrates: $5 \mathrm{mM}$ 4-nitrophenyl $\beta$-D-cellobioside, 4-nitrophenyl $\beta$-D-xylopyranoside and 4-nitrophenyl $\beta$-D-glucopyranoside, and $0.5 \%(\mathrm{w} / \mathrm{v})$ polygalacturonic acid, starch, CMC, xylan from beechwood (Sigma), wheat arabinoxylan, $\beta$-glucan and galactomannan (Megazyme). Assays were performed using $1 \mu \mathrm{g}$ protein of the concentrated secretomes in $50 \mathrm{mM}$ ammonium acetate buffer pH 5.5 for $4 \mathrm{~h}$ at $50{ }^{\circ} \mathrm{C}$. Assays with the synthetic substrates were stopped with $100 \mu \mathrm{l}$ of $1 \mathrm{M}$ sodium bicarbonate and the released 4-nitrophenolate was measured at $405 \mathrm{~nm}$. Reactions with polymeric substrates were stopped with $100 \mu \mathrm{l}$ of 3,5-dinitrosalicylic acid (DNS) and the released reducing sugars were measured at $540 \mathrm{~nm}$ [106]. All assays were performed in triplicate. One enzyme unit ( $1 \mathrm{U} ; \mu \mathrm{mol} / \mathrm{min}$ ) corresponds to the amount of enzyme that catalyzes the conversion of one micromole of substrate per minute under the assay conditions.

\section{Enzymatic saccharification}

Grass (sugarcane straw) and pine softwood (Pinus sp) lignocellulose were milled $(1.0 \mathrm{~cm}$ length $\times 1.0 \mathrm{~mm}$ thickness), followed by hydrothermal pretreatment and composition characterization $[107,108]$. Saccharification reactions were performed in $1 \mathrm{~mL}$ working volume with substrate load at $2 \%(\mathrm{w} / \mathrm{w})$ solids in $50 \mathrm{mM}$ sodium acetate buffer $\mathrm{pH} 5.0$ at $50{ }^{\circ} \mathrm{C}$ up to $48 \mathrm{~h}$ in a Thermomixer under $1000 \mathrm{rpm}$ agitation. The L. sulphureus secretome produced on SCB (as described above) was evaluated by replacing $15 \%$ of protein load from commercial enzymatic cocktails. FPAse activity was previously assayed in the enzymatic cocktail $[109,110]$ and the total protein load (equivalent to 15 FPU) was the combination $5: 1(\mathrm{w} / \mathrm{w})$ Celluclast $^{\circledR}$ :glucosidase from Aspergillus niger (Merck) per gram of dry substrate (Celluclast ${ }^{\circledR}$ at $150 \mathrm{mg}$ protein/mL corresponding to $115 \mathrm{FPU} / \mathrm{mL}$ ). Assays were performed in four replicates and the released sugars were measured by HPLC, as described below. Biomass conversion was calculated using glucan/xylan content in the biomass (pretreated/native) and the anhydrous correction factors of 1.13 for xylose and 1.1 for glucose [108, $111,112]$.

\section{HPLC analysis}

Glucose, xylose, and cellobiose were quantified in a liquid chromatography system (Waters 515 Pump, Water 717 plus Injector/Sampler) coupled to an Aminex HPX87H $(300 \times 7.8 \mathrm{~mm})$ column and equipped with a refractive index (RI) detector (Waters 410). Detector and column temperatures were set, respectively, to 40 and $45{ }^{\circ} \mathrm{C}$; $50 \mathrm{mM} \mathrm{H}_{2} \mathrm{SO}_{4}$ was used as a mobile phase at $0.6 \mathrm{ml} / \mathrm{min}$ flow rate; and $20 \mu \mathrm{l}$ injection volume.

\section{Supplementary Information}

The online version contains supplementary material available at https://doi. org/10.1186/s13068-021-01945-7.

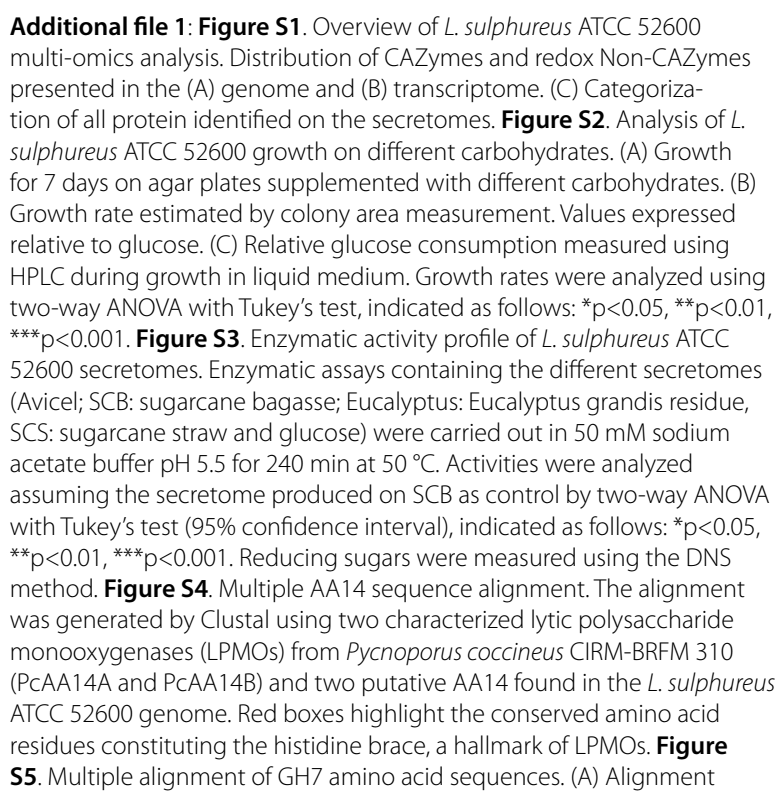


was performed by Clustal using basidiomycete cellobiohydrolases with identity higher than 65\% (GenBank: KIY52887, VDC00014, and OBZ744435). (B) Phylogenetic tree of GH7 amino acid sequences, which includes 14 characterized cellobiohydrolases according to UniProt, which are from Aspergillus aculeatus, Aspergillus niger, Aspergillus terreus, Aspergillus fischerianus, Aspergillus fumigatus, Aspergillus nidulans, Penicillium funiculosum, and Phanerochaete chrysosporium.

Additional file 2: Table S1. Main genes involved in brown-rot wood decay identified in L. sulphureus ATCC 52600 genome. Table S2. Differential expression of CAZymes in the transcriptome of L. sulphureus ATCC 52600. Table S3. Proteins identified with statistical significance in the exoproteomes of L. sulphureus ATCC 52600 cultivated on different substrates.

\section{Acknowledgments}

The authors are grateful to CAPES, CNPq, and FAPESP for financial support, Brazilian Biorenewables National Laboratory (LNBR/CNPEM) for the use of the Next Generation Sequencing Facility, Brazilian Biosciences National Laboratory (LNBio/CNPEM) for the use of the mass spectrometry facility; Professor Marcelo Brandão (CBMEG/UNICAMP) for helping with bioinformatics for proteomic analysis; Fernando Rodrigo Frederico (LEBBPOR/FEQ/UNICAMP) for technical support with HPLC analysis; Lívia Brenelli from LNBR/CNPEM for kindly providing the pretreated sugarcane straw used in the saccharification assays; Thamy Corrêa and LGE/UNICAMP for kindly providing steam-exploded SCB, SCS, and Eucalyptus lignocellulosic biomass. The authors thank Espaço da Escrita_-Pró-Reitoria de Pesquisa_UNICAMP—for the language services provided.

\section{Authors' contributions}

ACPO, TAG, and FMS designed and performed the experiments related to genomics and transcriptomics, analyzed data, and wrote the manuscript. FLF, CRFT, and AD designed and performed the experiments related to proteomics and biomass degradation. FLF, JAG, MVR, and CRFT designed and performed experiments, analyzed data, and wrote the manuscript. GT performed and analyzed the phylogenetic data and wrote the manuscript. GFP performed the bioinformatics analysis. MACS and RG performed HPLC analysis and collected data. JATP, MFA and SCR performed the pretreatment and characterization of pine lignocellulose. TTF provided resources. AD and FMS supervised the project. All authors read and approved the final manuscript.

\section{Funding}

ACPO and FLF were supported by FAPESP (São Paulo Research Foundation, 19/12860-0 and 19/21609-0, respectively) and Coordination for the Improvement of Higher Education Personnel (CAPES). MVR, CRFT, JAG, TAG, GT were supported by FAPESP fellowships. AD and FMS were supported by FAPESP grants no. 15/50612-8, 17/22669-0, 15/50590-4, and 20/05784-3. AD, CRFT, and FMS were also supported by CNPq (Brazilian Council for Scientific and Technological Development), grants no. 404654/2018-5 and 311457/2020-7; 420392/2018-1; 306279/2020-7 and 428527/2018-3, respectively. The authors acknowledge Coordenação de Aperfeiçoamento de Pessoal de Nível Superior-Brazil (CAPES/PROEX) -Finance Code 001—for support.

\section{Availability of data and materials}

The datasets generated for this study can be found in the Gene Expression Omnibus with the GEO accession number GSE151004.

\section{Declarations}

Ethics approval and consent to participate

Not applicable.

\section{Consent for publication}

Not applicable.

\section{Competing interests}

The authors declare that they have no competing interests.

\section{Author details}

${ }^{1}$ Department of Biochemistry and Tissue Biology, Institute of Biology, University of Campinas (UNICAMP), Campinas, SP, Brazil. ${ }^{2}$ Brazilian Biorenewables National Laboratory (LNBr), Brazilian Center for Research in Energy and Materials (CNPEM), Campinas, SP, Brazil. ${ }^{3}$ Department of Biological and Chemical Engineering (BCE), Aarhus University, 8200 Aarhus, Denmark. ${ }^{4}$ Interdisciplinary Center of Energy Planning (NIPE), University of Campinas (UNICAMP), Campinas, SP, Brazil. ${ }^{5}$ Chemical Engineering School, University of Campinas (UNICAMP), Campinas, SP, Brazil. ${ }^{6}$ Department of Food Engineering, Faculty of Food Engineering, University of Campinas (UNICAMP), Campinas, SP, Brazil. ${ }^{7}$ Department of Bioprocess and Biotechnology, College of Agricultural Sciences, São Paulo State University (UNESP), Botucatu, SP, Brazil. ${ }^{8}$ Department of Technological and Environmental Processes, University of Sorocaba (UNISO), Sorocaba, SP, Brazil. ${ }^{9}$ São Paulo Fungal Group, São Paulo, Brazil.

Received: 11 June 2020 Accepted: 1 April 2021

Published online: 17 April 2021

\section{References}

1. Mäkelä MR, Donofrio N, De Vries RP. Plant biomass degradation by fungi. Fungal Genet Biol. 2014;72:2-9.

2. Peralta RM, da Silva BP, Gomes Côrrea RC, Kato CG, Vicente Seixas FA, Bracht A. Enzymes from Basidiomycetes-Peculiar and efficient tools for biotechnology. Biotechnol Microb Enzym Prod Biocatal Ind Appl. 2017;119-149.

3. Rytioja J, Hildén K, Yuzon J, Hatakka A, de Vries RP, Mäkelä MR. Plantpolysaccharide-degrading enzymes from Basidiomycetes. Microbiol Mol Biol Rev. 2014;78:614-49.

4. Arantes V, Milagres AMF, Filley TR, Goodell B. Lignocellulosic polysaccharides and lignin degradation by wood decay fungi: the relevance of nonenzymatic Fenton-based reactions. J Ind Microbiol Biotechnol. 2011;38:541-55.

5. Cohen R, Suzuki MR, Hammel KE. Differential stress-induced regulation of two quinone reductases in the brown rot Basidiomycete Gloeophyllum trabeum. Appl Environ Microbiol. 2004;70:324-31.

6. Yelle DJ, Ralph J, Lu F, Hammel KE. Evidence for cleavage of lignin by a brown rot basidiomycete. Environ Microbiol. 2008;10:1844-9.

7. Arantes V, Jellison J, Goodell B. Peculiarities of brown-rot fungi and biochemical Fenton reaction with regard to their potential as a model for bioprocessing biomass. Appl Microbiol Biotechnol. 2012;94:323-38.

8. Zhang J, Presley GN, Hammel KE, Ryu JS, et al. Localizing gene regulation reveals a staggered wood decay mechanism for the brown rot fungus Postia placenta. Proc Natl Acad Sci USA.2016;113:10968-73.

9. Sista Kameshwar AK, Qin W. Systematic metadata analysis of brown rot fungi gene expression data reveals the genes involved in Fenton's reaction and wood decay process. Mycology. 2020;11:22-37.

10. Justo A, Miettinen O, Floudas D, Ortiz-Santana B, et al. A revised familylevel classification of the Polyporales (Basidiomycota). Fungal Biol. 2017; 121:798-824.

11. Mtui G, Masalu R. Extracellular enzymes from brown-rot fungus Laetiporus sulphureus isolated from mangrove forests of coastal Tanzania. Sci Res Essay. 2008;3:154-61.

12. Song J, Cui B-K. Phylogeny, divergence time and historical biogeography of Laetiporus (Basidiomycota, Polyporales). BMC Evol Biol. 2017;17:102.

13. Turkoglu A, Duru ME, Mercan N, Kivrak I, Gezer K. Antioxidant and antimicrobial activities of Laetiporus sulphureus (Bull.) Murrill. Food Chem. 2006;101:267-73.

14. Karaman M, Jovin E, Malbaša R, Matavuly M, Popović M. Medicinal and edible lignicolous fungi as natural sources of antioxidative and antibacterial agents. Phyther Res. 2010;24:1473-81.

15. Weber RWS, Mucci A, Davoli P. Laetiporic acid, a new polyene pigment from the wood-rotting basidiomycete Laetiporus sulphureus (Polyporales, Fungi). Tetrahedron Lett. 2004;45:1075-8.

16. Davoli P, Mucci A, Schenetti L, Weber RWS. Laetiporic acids, a family of non-carotenoid polyene pigments from fruit-bodies and liquid cultures of Laetiporus sulphureus (Polyporales, Fungi). Phytochemistry. 2005;66:817-23. 
17. Kartal SN, Terzi E, Yılmaz H, Goodell B. Bioremediation and decay of wood treated with ACQ, micronized ACQ, nano-CUO and CCA wood preservatives. Int Biodeterior Biodegrad. 2015;99:95-101.

18. Machuca A, Ferraz A. Hydrolytic and oxidative enzymes produced by white- and brown-rot fungi during Eucalyptus grandis decay in solid medium. Enzyme Microb Technol. 2001;29:386-91.

19. Hong MR, Kim YS, Joo AR, Lee JK, Kim YS, Oh DK. Purification and characterization of a thermostable $\beta-1,3-1,4-$ glucanase from Laetiporus sulphureus var miniatus. J Microbiol Biotechnol. 2009;19:818-22.

20. Valadares F, Gonçalves TA, Gonçalves DSPO, Segato F, et al. Exploring glycoside hydrolases and accessory proteins from wood decay fungi to enhance sugarcane bagasse saccharification. Biotechnol Biofuels. 2016; 9:110.

21. Horta MAC, Vicentini R, Delabona PDS, Laborda P, et al. Transcriptome profile of Trichoderma harzianum IOC-3844 induced by sugarcane bagasse. PLoS ONE. 2014; 9:1-17.

22. Nagy LG, Riley R, Tritt A, Adam C, et al. Comparative genomics of earlydiverging mushroom-forming fungi provides insights into the origins of lignocellulose decay capabilities. Mol Biol Evol. 2016; 33:959-70.

23. Martínez ÁT, Ruiz-Dueñas FJ, Martínez MJ, del Río JC, Gutiérrez A. Enzymatic delignification of plant cell wall: from nature to mill. Curr Opin Biotechnol. 2009;20:348-57.

24. Calonego FW, de Andrade MCN, Negrão DR, Rocha CD, et al. Behavior of the brown-rot fungus Gloeophyllum trabeum on thermally-modified Eucalyptus grandis wood. Floresta e Ambient. 2013; 20:417-23.

25. Hori C, Gaskell J, Igarashi K, Samejima M, et al. Genomewide analysis of polysaccharides degrading enzymes in 11 white- and brown-rot Polyporales provides insight into mechanisms of wood decay. Mycologia. 2013; 105:1412-27.

26. Riley R, Grigoriev IV, Hibbett DS, Otillar R, et al. Extensive sampling of basidiomycete genomes demonstrates inadequacy of the white-rot/ brown-rot paradigm for wood decay fungi. Proc Natl Acad Sci. 2014; 111:9923-8.

27. Sharma RK, Arora DS. Fungal degradation of lignocellulosic residues: an aspect of improved nutritive quality. Crit Rev Microbiol. 2015;41:52-60.

28. Segato F, Damásio ARL, de Lucas RC, Squina FM, Prade RA. Genomics review of holocellulose deconstruction by Aspergilli. Microbiol Mol Biol Rev. 2014;78:588-613.

29. de Vries RP, Riley R, Wiebenga A, Aguilar-Osorio G, et al. Comparative genomics reveals high biological diversity and specific adaptations in the industrially and medically important fungal genus Aspergillus. Genome Biol. 2017: 18:28.

30. Zhou X, Qi X, Huang H, Zhu H. Sequence and structural analysis of AA9 and AA10 LPMOs: an insight into the basis of substrate specificity and regioselectivity. Int J Mol Sci. 2019;20:4594.

31. Couturier M, Ladevèze S, Sulzenbacher G, Ciano L, et al. Lytic xylan oxidases from wood-decay fungi unlock biomass degradation. Nat Chem Biol.2018; 14:306-10.

32. Floudas D, Binder M, Riley R, Barry K, et al. The Paleozoic origin of enzymatic lignin decomposition reconstructed from 31 fungal genomes. Science. 2012; 336:1715-9.

33. Sützl L, Foley G, Gillam EMJ, Bodén M, Haltrich D. The GMC superfamily of oxidoreductases revisited : analysis and evolution of fungal GMC oxidoreductases. Biotechnol Biofuels. 2019;12:118.

34. Kerem Z, Jensen KA, Hammel KE. Biodegradative mechanism of the brown rot basidiomycete Gloeophyllum trabeum: Evidence for an extracellular hydroquinone-driven Fenton reaction. FEBS Lett. 1999:446:49-54

35. Levasseur A, Drula E, Lombard V, Coutinho PM, Henrissat B. Expansion of the enzymatic repertoire of the CAZy database to integrate auxiliary redox enzymes. Biotechnol Biofuels. 2013;6:41.

36. Daou M, Faulds CB. Glyoxal oxidases: their nature and properties. World J Microbiol Biotechnol. 2017;33:87.

37. Garajova S, Mathieu Y, Beccia MR, Bennati-Granier C, et al. Singledomain flavoenzymes trigger lytic polysaccharide monooxygenases for oxidative degradation of cellulose. Sci Rep. 2016; 6:28276.

38. Andlar M, Rezić T, Marđetko N, Kracher D, Ludwig R, Šantek B. Lignocellulose degradation: an overview of fungi and fungal enzymes involved in lignocellulose degradation. Eng Life Sci. 2018;18:768-78.

39. Loose JSM, Arntzen M, Bissaro B, Ludwig R, Eijsink VGH, Vaaje-Kolstad G. Multipoint precision binding of substrate protects lytic polysaccharide monooxygenases from self-destructive off-pathway processes. Biochem Am Chem Soc. 2018;57:4114-24.

40. Fernandez-fueyo E, Francisco J, Ferreira P, Floudas D, et al. Comparative genomics of Ceriporiopsis subvermispora and Phanerochaete chrysosporium provide insight into selective ligninolysis. Proc Natl Acad Sci. 2012;109:8352-8352.

41. Arantes V, Goodell B. Current understanding of brown-rot fungal biodegradation mechanisms: a review. ACS Symp Ser. 2014;1158:3-21.

42. Shah F, Mali T, Lundell TK. Polyporales brown rot species Fomitopsis pinicola: enzyme activity profiles, oxalic acid production, and $\mathrm{Fe}^{3+}$ _reducing metabolite secretion. Appl Environ Microbiol. 2018:84:e02662-e2717.

43. Mitchell AL, Attwood TK, Babbitt PC, Blum M, et al. InterPro in 2019: improving coverage, classification and access to protein sequence annotations. Nucleic Acids Res. 2019;47:351-60.

44. Wang W, Liu C, Ma Y, Liu X, Zhang K, Zhang M. Improved production of two expansin-like proteins in Pichia pastoris and investigation of their functional properties. Biochem Eng J. 2014;84:16-27.

45. Hage H, Miyauchi S, Virágh M, Drula E, et al. Gene family expansions and transcriptome signatures uncover fungal adaptions to wood decay. Environ Microbiol. 2021; 1462:2920-15423.

46. Hage $H$, Rosso M. Evolution of fungal carbohydrate-active enzyme portfolios and adaptation to plant cell-wall polymers. J Fungi. 2021;7:185.

47. Ohm RA, Riley R, Salamov A, Min B, Choi IG, Grigoriev IV. Genomics of wood-degrading fungi. Fungal Genet Biol. 2014;72:82-90

48. Martinez D, Challacombe J, Morgenstern I, Hibbett D, et al. Genome, transcriptome, and secretome analysis of wood decay fungus Postia placenta supports unique mechanisms of lignocellulose conversion. Proc Natl Acad Sci USA. 2009; 106:1954-9.

49. Savinova OS, Moiseenko KV, Vavilova EA, Chulkin AM, Fedorova TV, Tyazhelova TV, Vasina DV. Evolutionary relationships between the laccase Genes of Polyporales: orthology-based classification of laccase Isozymes and functional insight from Trametes hirsuta. Front Microbiol. 2019;10.

50. Wei D, Houtman CJ, Kapich AN, Hunt CG, Cullen D, Hammel KE. Laccase and Its role in production of extracellular reactive oxygen species during wood decay by the brown rot basidiomycete Postia placenta. Appl Environ Microbiol. 2010;76:2091-7.

51. Park N, Park S-S. Purification and characterization of a novel laccase from Fomitopsis pinicola mycelia. Int J Biol Macromol. 2014;70:583-9.

52. An H, Xiao T, Fan H, Wei D. Molecular characterization of a novel thermostable laccase PPLCC2 from the brown rot fungus Postia placenta MAD-698-R. Electron J Biotechnol. 2015;18:451-8.

53. Yelle DJ, Wei D, Ralph J, Hammel KE. Multidimensional NMR analysis reveals truncated lignin structures in wood decayed by the brown rot basidiomycete Postia placenta. Environ Microbiol. 2011;13:1091-100.

54. Tang JD, Perkins AD, Sonstegard TS, Schroeder SG, Burgess SC, Diehl SV. Short-read sequencing for genomic analysis of the brown rot fungus Fibroporia radiculosa. Appl Environ Microbiol. 2012;78:2272-81.

55. Gaskell J, Blanchette RA, Stewart PE, BonDurant SS, et al. Transcriptome and secretome analyses of the wood decay fungus Wolfiporia cocos support alternative mechanisms of lignocellulose conversion. Appl Environ Microbiol. 2016; 82:3979-87.

56. Zhang J, Schilling JS. Role of carbon source in the shift from oxidative to hydrolytic wood decomposition by Postia placenta. Fungal Genet Biol. 2017;106:1-8.

57. Presley GN, Schilling JS. Distinct growth and secretome strategies for two taxonomically divergent brown rot fungi. Appl Environ Microbiol. 2017:83:1-11

58. Presley GN, Zhang J, Schilling JS. A genomics-informed study of oxalate and cellulase regulation by brown rot wood-degrading fungi. Fungal Genet Biol. 2018;112:64-70.

59. Lundell TK, Mäkelä MR, Hildén K. Lignin-modifying enzymes in filamentous basidiomycetes - ecological, functional and phylogenetic review. J Basic Microbiol. 2010;50:5-20.

60. Peng M, Aguilar-Pontes MV, Hainaut M, Henrissat B, et al. Comparative analysis of basidiomycete transcriptomes reveals a core set of expressed genes encoding plant biomass-degrading enzymes. Fungal Genet Biol. 2018; 112:40-6. 
61. Amoroso A, Mancilla RA, González B, Vicuña R. Hydroquinone and $\mathrm{H}_{2} \mathrm{O}_{2}$ differentially affect the ultrastructure and expression of ligninolytic genes in the basidiomycete Ceriporiopsis subvermispora. FEMS Microbiol Lett. 2009;294:232-8.

62. Wymelenberg AV, Gaskell J, Mozuch M, Sabat G, et al. Comparative transcriptome and secretome analysis of wood decay fungi Postia placenta and Phanerochaete chrysosporium. Appl Environ Microbiol. 2010; 76:3599-610.

63. Eastwood DC, Floudas D, Binder M, Majcherczyk A, et al. The plant cell wall-decomposing machinery underlies the functional diversity of forest fungi. Science. 2011; 333:762-5.

64. Villares A, Moreau C, Bennati-Granier C, Garajova S, et al. Lytic polysaccharide monooxygenases disrupt the cellulose fibers structure. Sci Rep. 2017; 7:1-9.

65. Zhu Y, Plaza N, Kojima Y, Yoshida M, et al. Nanostructural analysis of enzymatic and non-enzymatic brown rot fungal deconstruction of the lignocellulose cell wall. Front Microbiol. 2020;11.

66. Szczerbowski D, Pitarelo AP, Zandoná Filho A, Ramos LP. Sugarcane biomass for biorefineries: comparative composition of carbohydrate and non-carbohydrate components of bagasse and straw. Carbohydr Polym. 2014;114:95-101.

67. Salazar MM, Grandis A, Pattathil S, Neto JL, et al. Eucalyptus cell wall architecture: clues for lignocellulosic biomass deconstruction. Bioenergy Res. 2016; 9:969-79.

68. Pauly M, Keegstra K. Cell-wall carbohydrates and their modification as a resource for biofuels. Plant J. 2008;54:559-68.

69. Canilha L, Chandel AK, Suzane Dos Santos Milessi T, Antunes FAF, et al. Bioconversion of sugarcane biomass into ethanol: An overview about composition, pretreatment methods, detoxification of hydrolysates, enzymatic saccharification, and ethanol fermentation. J Biomed Biotechnol.2012;2012:1-15.

70. Payne CM, Knott BC, Mayes HB, Hansson H, et al. Fungal cellulases. Chem Rev. 2015; 115:1308-448.

71. Cotoras M, Agosin E. Regulatory aspects of endoglucanase production by the brown-rot fungus Gloeophyllum trabeum. Exp Mycol. 1992;16:253-60.

72. Schilling JS, Tewalt JP, Duncan SM. Synergy between pretreatment lignocellulose modifications and saccharification efficiency in two brown rot fungal systems. Appl Microbiol Biotechnol. 2009;84:465-75.

73. Ferraz A, Rodríguez J, Freer J, Baeza J. Biodegradation of Pinus radiata softwood by white- and brown-rot fungi. World J Microbiol Biotechnol. 2001;17:31-4

74. Hatfield RD, Rancour DM, Marita JM. Grass cell walls: a story of crosslinking. Front Plant Sci. 2017;7:2056.

75. Kaffenberger JT, Schilling JS. Using a grass substrate to compare decay among two clades of brown rot fungi. Appl Microbiol Biotechnol. 2013;97:8831-40.

76. Malgas S, van Dyk JS, Pletschke BI. A review of the enzymatic hydrolysis of mannans and synergistic interactions between $\beta$-mannanase, $\beta$-mannosidase and a-galactosidase. World J Microbiol Biotechnol. 2015;31:1167-75.

77. Lee J-W, Kim H-Y, Koo B-W, Choi D-H, Kwon M, Choi I-G. Enzymatic saccharification of biologically pretreated Pinus densiflora using enzymes from brown rot fungi. J Biosci Bioeng. 2008;106:162-7.

78. Aguiar A, Gavioli D, Ferraz A. Extracellular activities and wood component losses during Pinus taeda biodegradation by the brown-rot fungus Gloeophyllum trabeum. Int Biodeterior Biodegrad. 2013;82:187-91.

79. Suckling ID, Jack MW, Lloyd JA, Murton KD, et al. A mild thermomechanical process for the enzymatic conversion of radiata pine into fermentable sugars and lignin. Biotechnol Biofuels. 2017; 10:61.

80. Couturier M, Navarro D, Chevret D, Henrissat B, et al. Enhanced degradation of softwood versus hardwood by the white-rot fungus Pycnoporus coccineus. Biotechnol Biofuels. 2015; 8:216.

81. Bolger AM, Lohse M, Usadel B. Trimmomatic: a flexible trimmer for Illumina sequence data. Bioinformatics. 2014;30:2114-20.

82. Leggett RM, Clavijo BJ, Clissold L, Clark MD, Caccamo M. Next clip: an analysis and read preparation tool for nextera long mate pair libraries. Bioinformatics. 2014;30:566-8.

83. Zerbino DR, Birney E. Velvet: algorithms for de novo short read assembly using de Bruijn graphs. Genome Res. 2008;18:821-9.
84. Boetzer M, Henkel CV, Jansen HJ, Butler D, Pirovano W. Scaffolding preassembled contigs using SSPACE. Bioinformatics. 2011;27:578-9.

85. Walker BJ, Abeel T, Shea T, Priest M, et al. Pilon: an integrated tool for comprehensive microbial variant detection and genome assembly improvement. PLoS ONE. 2014; 9:e112963.

86. Simão FA, Waterhouse RM, loannidis P, Kriventseva EV, Zdobnov EM BUSCO: assessing genome assembly and annotation completeness with single-copy orthologs. Bioinformatics. 2015;31:3210-2.

87. Hoff KJ, Lange S, Lomsadze A, Borodovsky M, Stanke M. BRAKER1: unsupervised RNA-Seq-based genome annotation with GeneMark-ET and AUGUSTUS. Bioinformatics. 2016;32:767-9.

88. Apweiler R, Bateman A, Martin MJ, O'Donovan C, et al. Activities at the universal protein resource (UniProt). Nucleic Acids Res. 2014; 42:191-8.

89. Huerta-Cepas J, Szklarczyk D, Forslund K, Cook H, et al. EGGNOG 4.5: a hierarchical orthology framework with improved functional annotations for eukaryotic, prokaryotic and viral sequences. Nucleic Acids Res. 2016:44:286-93.

90. Finn RD, Coggill P, Eberhardt RY, Eddy SR, et al. The Pfam protein families database: towards a more sustainable future. Nucleic Acids Res. 2016;44:279-85.

91. Petersen TN, Brunak S, Von Heijne G, Nielsen H. SignalP 4.0: discriminating signal peptides from transmembrane regions. Nat Methods. 2011;8:785-6.

92. Krogh A, Larsson B, Von Heijne G, Sonnhammer ELL. Predicting transmembrane protein topology with a hidden Markov model: application to complete genomes. J Mol Biol. 2001;305:567-80.

93. Zhang $H$, Yohe $T$, Huang L, Entwistle $S$, et al. DbCAN2: a meta server for automated carbohydrate-active enzyme annotation. Nucleic Acids Res. 2018:46:95-101.

94. Katoh K, Standley DM. MAFFT multiple sequence alignment software version 7: improvements in performance and usability. Mol Biol Evol. 2013;30:772-80.

95. Kück P, Longo GC. FASconCAT-G: extensive functions for multiple sequence alignment preparations concerning phylogenetic studies. Front Zool. 2014;11:81.

96. Stamatakis A. RAxML version 8: a tool for phylogenetic analysis and post-analysis of large phylogenies. Bioinformatics. 2014;30:1312-3.

97. Kim D, Pertea G, Trapnell C, Pimentel H, Kelley R, Salzberg SL. TopHat2: accurate alignment of transcriptomes in the presence of insertions, deletions and gene fusions. Genome Biol. 2013;14:R36.

98. Love Ml, Huber W, Anders S. Moderated estimation of fold change and dispersion for RNA-seq data with DESeq2. Genome Biol. 2014;15:1-21.

99. Pontecorvo G, Roper JA, Chemmons LM, Macdonald KD, Bufton AWJ. The genetics of Aspergillus nidulans. Adv Genet. 1953;5:141-238.

100. Schneider CA, Rasband WS, Eliceiri KW. NIH Image to ImageJ: 25 years of image analysis. Nat Methods. 2012;9:671-5.

101. Laemmli UK. Cleavage of structura I proteins during the assembly of the head of Bacteriophage T4. Nature. 1970;227:680-5.

102. Shevchenko A, Wilm M, Vorm O, Mann M. Mass spectrometric sequencing of proteins from silver-stained polyacrylamide gels. Anal Chem. 1996:68:850-8.

103. Rubio MV, Zubieta MP, Franco Cairo JPL, Calzado F, et al. Mapping $\mathrm{N}$-linked glycosylation of carbohydrate-active enzymes in the secretome of Aspergillus nidulans grown on lignocellulose. Biotechnol Biofuels. 2016; 9:168.

104. Keller A, Nesvizhskii Al, Kolker E, Aebersold R. Empirical statistical model to estimate the accuracy of peptide identifications made by MS/MS and database search. Anal Chem. 2002;74:5383-92.

105. Käll L, Storey JD, MacCoss MJ, Noble WS. Assigning significance to peptides identified by tandem mass spectrometry using decoy databases. J Proteome Res. 2008;7:29-34.

106. Miller GL. Use of dinitrosalicylic acid reagent for determination of reducing sugar. Anal Chem. 1959;31:426-8.

107. Brenelli LB, Figueiredo FL, Damasio A, Franco TT, Rabelo SC. An integrated approach to obtain xylo-oligosaccharides from sugarcane straw: from lab to pilot scale. Bioresour Technol. 2020;313:123637.

108. Sluiter A, Hames B, Ruiz R, Scarlata C, Sluiter J, Templeton D, Crocker D. Determination of structural carbohydrates and lignin in biomass. 
Technical Report NREL/TP-510-42618. National Renewable Energy Laboratory. 2011.

109. Eveleigh DE, Mandels M, Andreotti R, Roche C. Measurement of saccharifying cellulase. Biotechnol Biofuels. 2009;2:21.

110. Camassola M, Dillon JPA. Cellulase determination: Modifications to make the filter paper assay easy, fast, practical and efficient. J Anal Bioanal Tech. 2012;01:10-3.

111. Selig M, Weiss N, Ji Y. Enzymatic saccharification of lignocellulosic biomass. Laboratory Analytical Procedures NREL/TP-510-42629. National Renewable Energy Laboratory. 2008.
112. Brenelli L, Squina FM, Felby C, Cannella D. Laccase-derived lignin compounds boost cellulose oxidative enzymes AA9. Biotechnol Biofuels. 2018:11:1-12.

\section{Publisher's Note}

Springer Nature remains neutral with regard to jurisdictional claims in published maps and institutional affiliations.
Ready to submit your research? Choose BMC and benefit from:

- fast, convenient online submission

- thorough peer review by experienced researchers in your field

- rapid publication on acceptance

- support for research data, including large and complex data types

- gold Open Access which fosters wider collaboration and increased citations

- maximum visibility for your research: over $100 \mathrm{M}$ website views per year

At BMC, research is always in progress.

Learn more biomedcentral.com/submissions 